\title{
The cost of capital for power generation in atypical capital market conditions
}

\author{
Paul Simshauser* \\ Level 6, 144 Edward Street \\ Brisbane, QLD 4001 \\ Abstract \\ Determining the cost of capital in the energy sector requires considerable care. Whether \\ being derived by firms, stock analysts, policymakers or regulators, the consequence of \\ error is amplified because the energy sector is the world's most capital-intensive. No \\ other cost variable has a greater impact on electricity price/cost estimates. Historically, \\ the Capital Asset Pricing Model could be applied mechanistically and produce reliable \\ estimates for equity costs. But the Global Financial Crisis produced atypical capital \\ market conditions and a mechanistic application will produce results that are intuitively \\ erroneous. The model is not broken, but inputs require professional judgement and \\ adjustment...
}

Keywords: CAPM, Power Generation, Electricity Prices. JEL Codes: G12, L11, L94, and Q40.

\section{Introduction}

Investing in power generating equipment involves vast financial commitments by firms due to the highly capital-intensive nature of the industry. Whether the market for electricity is vertically integrated and regulated, or disaggregated and intensely competitive, achieving an efficient allocation of capital to maximise total welfare can be greatly hindered by selecting an inappropriate cost of capital in investment decision making or policymaking.

In policymaking, if benchmarks used over-state the cost of capital, electricity prices will rise above the optimal level, consumer welfare will be adversely affected and resource allocation to other industries may be scaled-back to inefficient levels. Conversely, underestimation can lead to policy settings that benefit consumers in the short run but the associated wealth transfers adversely affect future industry investment, competition and innovation, and in the long run will eventually harm consumers. Identifying a theoretically sound and pragmatic measure of the cost of capital is therefore of vital importance to investors, policymakers, and in turn, the overall efficiency of the macro economy.

Firms, stock analysts, regulators and policymakers frequently rely on the Capital Asset Pricing Model (CAPM) to produce estimates for the cost of equity. The CAPM, developed by Sharpe (1964) and Lintner (1965), was a truly ground-breaking contribution to economic theory and has helped practitioners and academics considerably ever since. But it is an economic estimation model, and all models are only as good as their inputs, and inputs to any model used in practice inevitably require considerable professional judgement.

At any time during the past five years since the collapse of Lehman Brothers in 2008 - the official starting date of the Global Financial Crisis - many electricity firms around the world will have no doubt encountered some form of policy uncertainty vis-à-vis the cost of equity capital, whether used as a direct input to set regulated prices or as an input to broader energy industry policymaking. In capital-intensive industries, few factors could be more damaging to achieving efficient outcomes than a dynamic inconsistency problem. When perceptions of 'policy uncertainty' become enshrined due to erratic, opportunistic or unpredictable changes by

\footnotetext{
- Paul Simshauser is the Chief Economist at AGL Energy Ltd and Professor of Economics at Griffith University. The author is grateful for the considerable help and advice from Professor Stephen Gray (The University of Queensland), David Gray (Equity Capital Markets, JP Morgan) and Sarah Bourne (Investment Banking, JP Morgan). 
regulators or policymakers, firms will act rationally in response (Kydland and Prescott, 1977; Rogoff, 1985; Taylor, 1985; Batabyal, 1996; Virag, 1999; Haubrich, 2000; Brito et al. 2011). Indeed, the literature highlights that only one erratic decision is required to create a time inconsistency problem.

For over a century, electricity utilities have managed to deal with substantial business uncertainty and the techniques for doing so have become ever more sophisticated due to advances in engineering, information technology and finance. ${ }^{1}$ The electricity industry invariably navigates business uncertainty. However, dynamic inconsistency and policy uncertainty are much more complex to navigate because investment commitments in electricity assets are especially longlived ( $30+$ years). Long run market outcomes for consumers under conditions of dynamic inconsistency are likely to be favourable only by chance.

The way in which any industrial firm deals with the downside risk associated with uncertainty is to (1) mitigate through managerial action, or if this is not possible, (2) procure insurance over the risk. Where neither option is practical, business activity is (3) withdrawn, or (4) 'priced accordingly'. When risks are 'priced accordingly', associated premiums are typically substantial, and if driven by dynamic inconsistency will adversely impact total welfare.

Dynamic inconsistency problems in Australia's merchant electricity markets will produce different responses in different segments. For example, in the market for renewable energy, dynamic inconsistency has contributed to a virtual investment blackout. Firms expect the $20 \%$ renewable target in 2020 to be modified, and so they have slowed their renewable plant investment commitments. Now so little time is left to meet the fixed volumetric target that policymakers will almost certainly be forced to adjust the policy downwards. ${ }^{2}$

On the other hand, the market for reliability services (i.e. adequate thermal power generation to meet reliability standards) will be met with a very different response to a dynamic inconsistency problem. Even acute policy uncertainty is unlikely to result in the complete withdrawal of business activity. The reason for this is that deregulated electricity markets have an interesting dynamic - wholesale prices can spike to truly extreme levels. In Australia, the average annual spot price is c. $\$ 50 / \mathrm{MWh}$ but half-hourly spot prices can and do reach the market price cap of $\$ 13,100 / \mathrm{MWh}$. Such extreme prices have bankrupted electricity firms within days when running 'short positions' against the spot market. Accordingly, risk response options (2) and (3) are not viable. However, option 1 and 4 (mitigate the risk through managerial action but 'price the risk accordingly') will feature prominently.

In the presence of a dynamic inconsistency problem, investment in low capital cost 'peaking' plant represents a logical capital allocation response by electricity utilities because the marginal committed capital-at-risk is minimised as Nelson et al. (2010) explain. But while such plant have a low capital cost, they also have high operating costs and if they are over-represented in the aggregate supply stock, future electricity prices will be raised above efficient levels. Nelson et al. (2010) quantified the costs associated with dynamic inconsistency of carbon policy in Australia's National Electricity Market (NEM) whereby the investment preferences of firms displayed a distinct bias away from optimality and towards low-capital, high-operating cost peaking plant. Modelling results demonstrated efficiency losses of $\$ 2$ billion per annum by 2020 due to adverse technology selection.

\footnotetext{
${ }^{1}$ For example, changes in maintenance philosophy (from reactive to condition monitoring), the creation of real-time spot electricity markets and the construction and pricing of derivatives contracts, respectively.

${ }^{2}$ The $20 \%$ Renewable Energy Target is expressed as a fixed volume target of $41,000 \mathrm{GWh}$ by 2020 and was set in the late $2000 \mathrm{~s}$. However, recent contractions in energy demand and projections of slower growth rates to 2020 , it is thought that $41,000 \mathrm{GWh}$ will represent more than $25 \%$ of total energy production. Policymakers are likely to reduce the fixed target to some lower level, or may even set a target of $20 \%$ of 'actual' energy production (i.e. not a fixed volume target).
} 
A limitation of the Nelson et al (2010) analysis was that the cost of capital was held constant in the presence of a particularly large dynamic inconsistency problem. Yet under such conditions the cost of capital can be expected to rise above efficient levels. This topic was analysed in Simshauser and Nelson (2012) and using data from capital market surveys, they found that the marginal cost of debt capital for thermal plant would rise by 200 basis points (bps) resulting in additional efficiency losses of $\$ 1.6$ billion per annum. Similar studies by Rathmann et al. (2011) and Varadarajan et al. (2011) found policy clarity around renewable energy pricing led to variations in the cost of debt of between 200-600bps, while Neuhoff and DeVries (2004) found a cost of debt premium of up to 600bps in markets where electricity prices were highly cyclical and did not enable end-to-end pricing at long run costs.

What happens when the cost of capital itself is the subject of a dynamic inconsistency problem in policymaking? In theory at least, the flow of investment would evaporate because the expected returns would fall below the marginal efficiency of capital - the opposite outcome identified by Averch and Johnson (1962), who demonstrated that high rates of return provide a regulatory incentive for electric utilities to over-capitalise or 'gold-plate' their systems. In a practical sense, short run suboptimal investment is more likely with costs and prices rising above the efficient level. However, if such a response becomes enduring, security of supply could ultimately be compromised as Simshauser and Nelson (2014) explain. Using Australian data, they demonstrate that security of supply breaches are followed by politicised policy 'over-reactions' and an associated rush of capital expenditure to re-stock capacity. This then results in severe excess capacity in subsequent periods - in some instances spanning more than 20 years in duration.

The purpose of this article is to explore how to apply the CAPM in atypical capital market conditions such as those that have existed from 2008 to the time of writing in 2013. This article applies these concepts to power generation and is structured as follows. Section 2 briefly provides some context of the cost of capital by clearing defining Normal Profit. Section 3 then reviews the CAPM and discusses how it can be applied in atypical capital market conditions. Section 4 presents a Levelised Cost of Electricity Model while Section 5 outlines key data inputs and model results. Section 6 uses these results in a partial equilibrium model and discusses implications for policymaking. Concluding remarks follow.

\section{What is Normal Profit?}

Normal Profit can be defined as the firm's total cost of production, including the opportunity cost of funds employed. The 'opportunity cost of funds employed' requires further clarification, however. The 'Accounting' treatment of equity costs is inadequate because it treats such capital resources as a 'residual claim' over available profits. In economics, no such assumption is made - equity returns are treated as a fixed cost, just as debt-related interest expenses are considered fixed costs under accounting principles. And so a firm's total cost of production includes all costs, including the opportunity cost of capital which translates to a normal (i.e. fair) level of profit to equity investors. The importance of incorporating equity costs as a charge against revenue, a foreign concept to accountants, has long been accepted in economic theory as a prerequisite to the survival of the firm as Thompson and Formby (p. 241, 1993) noted long ago:

... Whenever the profitability of a business is consistently below what can generally be earned in other enterprises of equivalent business risk, stockholders can be expected to seek greener pastures for their investment funds. Because additional resources and capital will tend to be withheld from an enterprise if profits fall below normal levels for sustained periods, it is appropriate to consider this minimum profitability as a cost. It is a cost in the sense that unless revenues from the firm's operations are adequate to provide acceptable rewards to stockholders, the capital funds needed to sustain operations will dry up and the firm, in time, will wither and die. In other words, in the long run some minimal amount of profit is a condition of survival... 
In my experience, a surprising number of policymakers, regulators and microeconomics professionals (from industry and from academia) misinterpret the appropriate quantitative definition and therefore value of the marginal cost of capital. The reason for this, I suspect, is that the theoretical construct of 'opportunity cost' must shift from theory to practice, all the while ensuring that in the process the result does not violate the basic axioms and real world constraints of debt capital market credit metrics and taxation implications - all of which are known to be important in practice when defining the marginal efficiency of equity and debt capital. To be clear, the shift from theory to practice is grounded in financial economics, not in microeconomics.

\section{Defining the marginal cost of capital in atypical capital market conditions}

The most important variable in determining the wholesale cost of electricity is the cost of capital due to the capital-intensive nature of power generation as Section 6 later demonstrates. The cost of debt is directly observable from debt capital markets. The cost of equity capital is not - it is the subject of economic estimation models. In power generation, the estimated marginal cost of equity capital is not a single number either. For example, a regulated power plant will have a lower cost of equity than a merchant power plant, all things being equal. And for merchant power generation, it will be quite different for the two most prominent business combinations (1) integrated merchant utilities with an investment-grade credit rating, and (2) project financed merchant power producers.

The viable level of debt within these two business combinations can be quantified through detailed power project finance modelling. Simshauser and Ariyaratnam (2014) explore this in considerable detail and modelling results demonstrate that the two business combinations have very different gearing levels - with project financing typically ranging from $60-80 \%$ and investment-grade entities exhibiting values of $30-40 \%$. The expected cost of equity is different for each business combination - the marginal efficiency of equity capital for a project finance will gravitate towards $15-16 \%$, whereas marginal equity costs for an investment-grade integrated merchant utility is typically $11-12 \%$.

Since the marginal cost of equity capital must be estimated, a brief discussion of its derivation is warranted, noting that a truly vast amount of literature on this topic exists from a mechanistic perspective commencing with Sharpe (1964) and Lintner (1965). Section 3.2 will focus on the key elements of its application in 'atypical capital market conditions' - where there is comparatively little literature readily available.

\subsection{Estimating the cost of equity: the Sharpe-Lintner Capital Asset Pricing Model}

With any portfolio of investments, there is always some component of risk that affects all asset classes, known as 'systematic' or market risk. Systematic risks are those variables that affect the entire economy, albeit some assets are affected by these variables more than others. A good example of systematic risk is a rise in consumer prices. All things being equal, rising general inflation is likely to lead to higher interest rates, labour costs or both (amongst other impacts). Such movements in these economic variables generally adversely affect all firms, although for power generation, interest rate changes are amplified given the capital-intensive nature of the sector.

Non-systematic risks on the other hand are those that affect a single or a small group of stocks, and can therefore be essentially eliminated at minimal cost through diversification at the investor level. An example of a non-systematic risk for power generation is mild weather, which is usually associated with adverse commodity sales. Since non-systematic risk can be virtually eliminated at almost no cost by diversification at the investor level, there is no reward for bearing it. However, systematic risk cannot be eliminated through diversification, and thus, stockholders 
must be rewarded by suitable (expected) returns. The cost of equity capital is most typically approximated through the Sharpe-Lintner CAPM. ${ }^{3}$ The model is defined as follows:

$K_{e}=R_{f}+\left(R_{m}-R_{f}\right) \cdot \beta_{i}$

Where: $K e \quad=$ post-tax cost of equity capital

$R_{f} \quad=$ the risk free rate of return

$R_{m} \quad=$ the expected market return

$\beta_{i} \quad=$ the equity beta for the $i^{\text {th }}$ firm, which ex ante can be used as predictive, and

$$
\beta_{i} \quad=\frac{\operatorname{Cov}\left(R_{i}, R_{m}\right)}{\sigma_{m}^{2}}
$$

Where: $R_{i} \quad=$ the returns from the $i^{\text {th }}$ firm

$R_{m} \quad=$ the returns from the stock market as a whole

$\sigma_{m}^{2} \quad=$ the variance of market returns as a whole

The intercept term $\left(R_{f}\right)$ is the risk free rate and is a purely theoretical construct. In practice however, the current yield of long-dated government bonds are used as a proxy. Regulators and policymakers in the NEM typically use contemporaneous values for $R_{f}{ }^{4}$ The expected return of the total market $(\mathrm{Rm})$ on the other hand is approximated by reference to very long run average returns from the stock market over and above long dated government rates at the time (i.e. Rm$R f)$. Over the last 128 years the calculation of $(R m-R f)$ known as the Market Risk Premium $(M R P)$ has averaged 6.1\% (Brailsford, Handley and Maheswaran, 2012). Shapiro et al. (2013) report that the nominal value for $R m$ over the past 100 years in Australia has averaged $11.8 \%$ and thus $R f$ has averaged $5.7 \%$.

The crucial factor in the CAPM is the equity beta $\left(\beta_{i}\right)$ for the $i^{\text {th }}$ firm- which is concerned with the measure of systematic risk for a company. As equation (2) implies, a firm that has the same general risk characteristics as the aggregate stock market will return a $\beta_{i}$ equal to 1.0. The generation business unit of an investment grade merchant utility, for example, would typically have a $\beta_{i}$ in the range of 0.95 to 1.15 as IPART (2013) explains. The higher leverage associated with project financed merchant power plants will produce markedly higher earnings volatility and therefore will have a $\beta_{i}$ greater than 1.0, typically in the range of 1.5 to $1.8 .^{5}$ Of course, while $\beta_{i}$ is mathematically defined based on equation (2), this is an historical calculation and in practice $\beta_{i}$ and the CAPM must be used to define (expected) future returns.

\subsection{Applying the Sharpe-Linter CAPM in atypical capital market conditions}

Throughout most of the last 20 years, the CAPM could be mechanistically applied to the power generation industry as outlined in Section 3.1 and produce stable and reliable estimates for $K_{e}$. However, the collapse of Lehman Brothers in September 2008 and the Global Financial Crisis that followed produced atypical capital market conditions. A 'mechanistic' application of the CAPM anytime since October 2008 through to the time of writing in 2013 would produce results that are intuitively, and evidently, erroneous.

\footnotetext{
${ }^{3}$ There are other equity cost estimation models such as Fama and French's (1997) three factor model. However in the Australian energy sector, the CAPM is most widely used.

${ }^{4}$ For example, $R_{f}$ is often determined in regulatory determinations by reference to the 30 -day rolling average yield on 10 -Year Australian Government Bonds.

${ }^{5}$ The value foe $\beta_{i}$ is based on the work undertaken by the NSW economic regulator, IPART (2013) and PWC (2013). The range for $\beta_{i}$ was found to be $0.95-1.15$ and in this article the midpoint of 1.05 is used. Using the gearing levels implied in the IPART (2013) analysis, the Asset Beta $\beta_{a}$ value which appears later in Table 2 can be expressed as $\beta_{a}=\beta_{V I} /\left[\left(1+\frac{\mathrm{D}_{V I}}{E_{V I}}\right)\right.$. (1- $\left.\left.\tau_{e}\right)\right]$ where $E$ is the value of equity, $\mathrm{D}$ is the value of debt and $\tau_{e}$ is the effective tax rate. This can then be rearranged to produce an equity beta for Merchant Power Plant such that $\beta_{M P P}=\beta_{a} \cdot\left[\left(1+\frac{D_{M P P}}{E_{M P P}}\right) \cdot\left(1-\tau_{e}\right)\right]=1.58$, which is within the range of 1.5-1.8.
} 
To be perfectly clear from a definitional perspective, the reference to 'atypical capital market conditions' is not intended to be a reference to an economic recession. Reference to 'atypical' relates to a relatively unique situation whereby yields on government bonds are uncharacteristically low - which implies a general state of 'loose credit' - while simultaneously the market for corporate debt is contracting, perhaps sharply, but above all exhibits rising spreads. Bernanke (1983) shows that the Great Depression and in particular, the 1930-33 financial crisis in the US exhibited atypical conditions not observed in other economic recessions. The prime cause was the 1930-33 financial crisis and associated insolvency of large numbers of banks. The Global Financial Crisis of 2008-09 produced outcomes in capital markets that are directionally consistent with Bernanke's (1983) description of 1930-33.

The relevance of atypical capital market conditions to the CAPM is that a mechanistic application uses a very long run data set for both variables in the $M R P$ calculation (i.e. $R m-R f$ ), in the present case 128 years, but simultaneously uses a contemporaneous value for the intercept term $R_{f}$. This combination is problematic in atypical capital market conditions and is demonstrated in Figure 1 . Here, the CAPM is mechanistically applied to produce monthly $K_{e}$ estimates for a power generator from July 1997 through to June 2013 assuming that $M R P=6.1 \%, \beta_{i}=1.05$ which is relevant to a generation business with an investment-grade credit rating, and the intercept term $R_{f}$ at contemporaneous 10-Year Government Bond values. Notice by following a mechanistic application of the CAPM, the value of marginal equity costs $K_{e}$ falls once the 2008 financial crisis sets in.

\section{Figure 1: $\quad$ 10-Year Govt Bond Yields vs. Mechanistic CAPM Estimate}

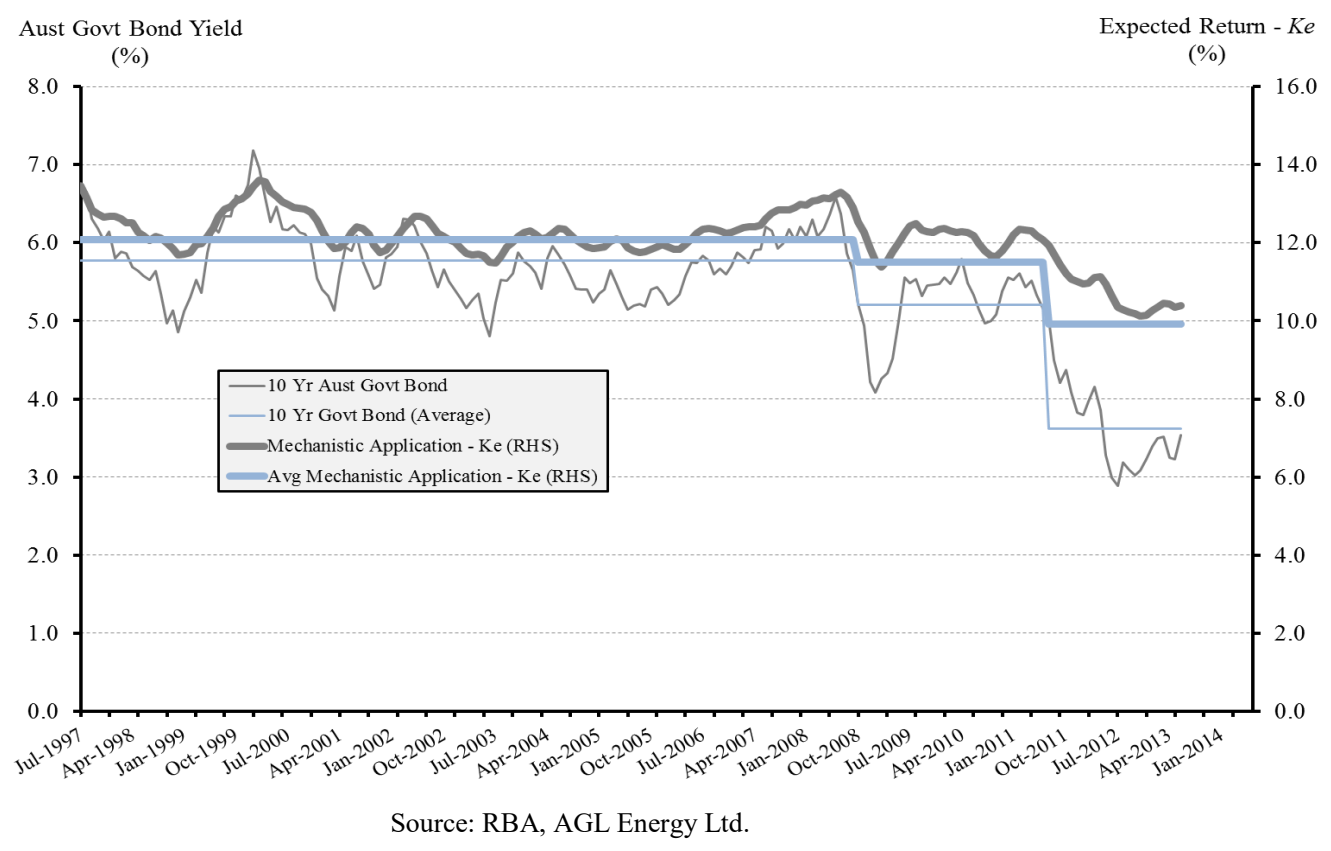

In this instance, falling government bond yields gives the appearance that $K e$ is also falling. But in a financial crisis, this is an erroneous conclusion as Bernanke (1983, p266) observed in the context of the 1929-33 US episode:

...the idea that low yields on Treasury [bonds] ... during this time signalled a general state of "easy money" is mistaken; money was easy for a few safe borrowers, but difficult for everyone else. An indicator of the strength of lender preferences for safe liquid assets (and hence of the difficulty of risky borrowers in obtaining funds) is the yield differential between Baa corporate bonds and Treasury bonds... 
Figure 2 presents historical credit spreads between Australian Government Bonds and BBB rated corporate bonds from January 2000 through to June 2013, along with Bernanke's (1983) US Baa corporate bond spread data from the Great Depression which runs from July 1929 to March 1933. ${ }^{6}$ These data are contrast with the mechanistically determined average values for $\mathrm{Ke}$ as derived in Figure 1. The Figure 2 results are important with respect to the application of the CAPM. First, note the shape of the US Baa corporate spread data trace from the Great Depression - Bernanke (1983) explains that the sharp rise in spreads coincided with an accelerating rate of bank failures. The 1929-33 data has been aligned to the Australian BBB bond spread data by matching the peak of the bank failures as reported by Bernanke (1983) with the collapse of Lehman Brothers in September 2008. As an aside, the correlation coefficient between the two data sets is 0.88 . Note that just as 10 year government bond yields fall sharply in 2008, BBB corporate spreads rise sharply and coincide with the collapse of Lehman Brothers in September 2008. In these circumstances, institutional investors adopted a "risk off" approach, meaning that investment funds shift from risky corporate bonds and equities towards low risk Treasury bonds or Australian Government bonds - hence the falling value of 10-year Government bonds and rising BBB spreads.

Figure 2:

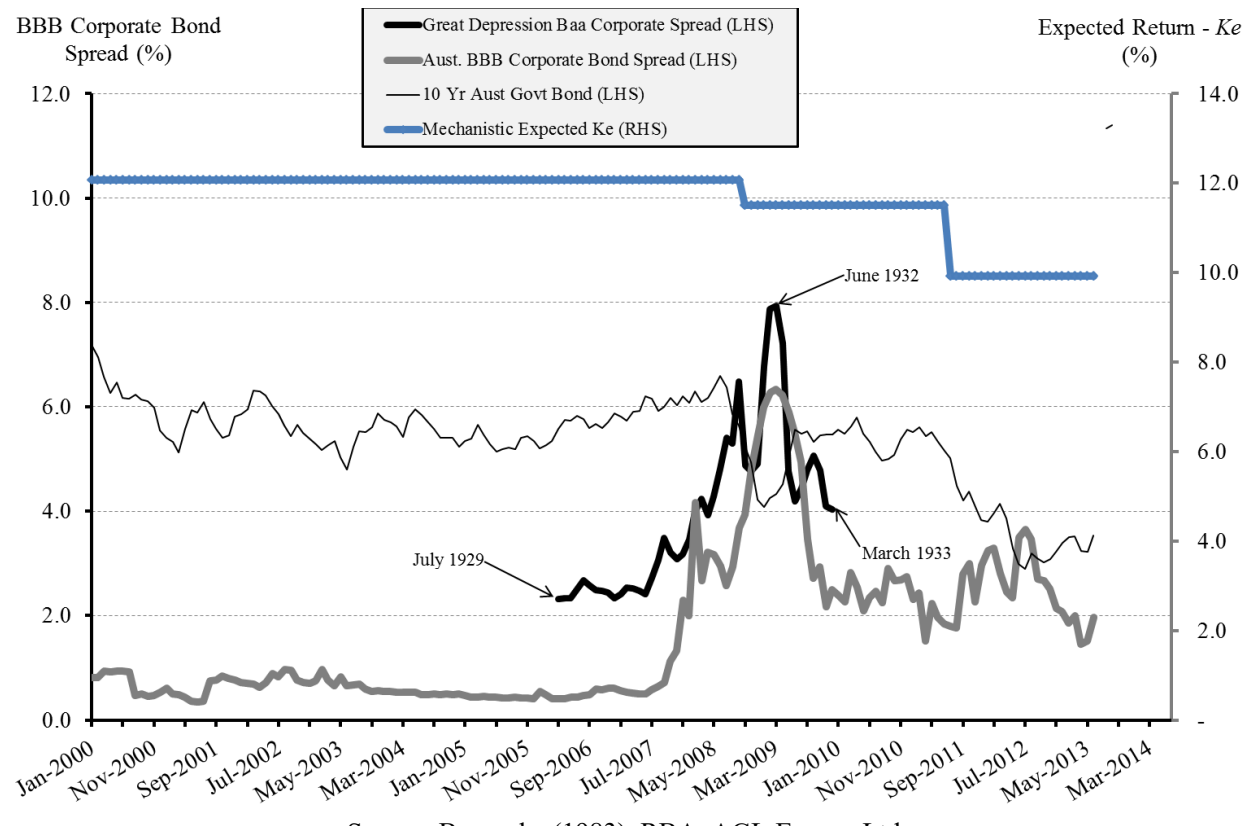

Source: Bernanke (1983), RBA, AGL Energy Ltd.

As an economic model reliant on assumptions and data inputs to produce estimates of $K_{e}$, when applied mechanistically, the CAPM tells us that equity investors would accept lower risk premiums in the middle of a financial crisis as Figure 2 highlights. So when government bonds are trading at record lows, $K_{e}$ is apparently valued at historic lows. Gray (2013b) demonstrates such an approach erroneously suggests that the value of $K_{e}$ is the lowest at any point in the last 40 years. From a practical perspective, it is difficult to imagine the conditions where corporate debt investors require substantially higher premiums while simultaneously, equity investors accept the lowest risk premiums on record. Empirical evidence certainly collides with any such notion. Figure 3 illustrates that during Australia's record year of Equity Capital Market (ECM) raisings in $2009^{7}$, activity was carried out at what could only be described as deep discounts to listed equity pricing. With the Lehman Brothers collapse in September 2008, unsurprisingly, 2009 represented the height of discounted ECM raisings. The 'All ECM Products' registered average discounts of $21 \%$ in 2009 (up from 12\% in 2007), while Placements in 2009 were discounted by $12 \% \frac{1}{2} \%$ (up

${ }^{6}$ Standard \& Poor's 'BBB' rating is essentially equivalent to Moody's 'Baa' rating.

${ }^{7}$ For an analysis of year-on-year capital raisings by ASX-listed entities from 1990-2009, see Simshauser (2010). 
from 5\% in 2007) and Rights Issues were discounted by an average of $26 \%$ (up from $11 \frac{1}{2} \%$ in 2007) as Figure 3 demonstrates. In other words, equity risk premiums, as with corporate debt risk premiums, were above average and as a result, values for $\mathrm{Ke}$ were actually higher, not lower, than historical averages and certainly not at historic lows.

Figure 3: $\quad$ Equity Capital Market Discounts 2007-2013

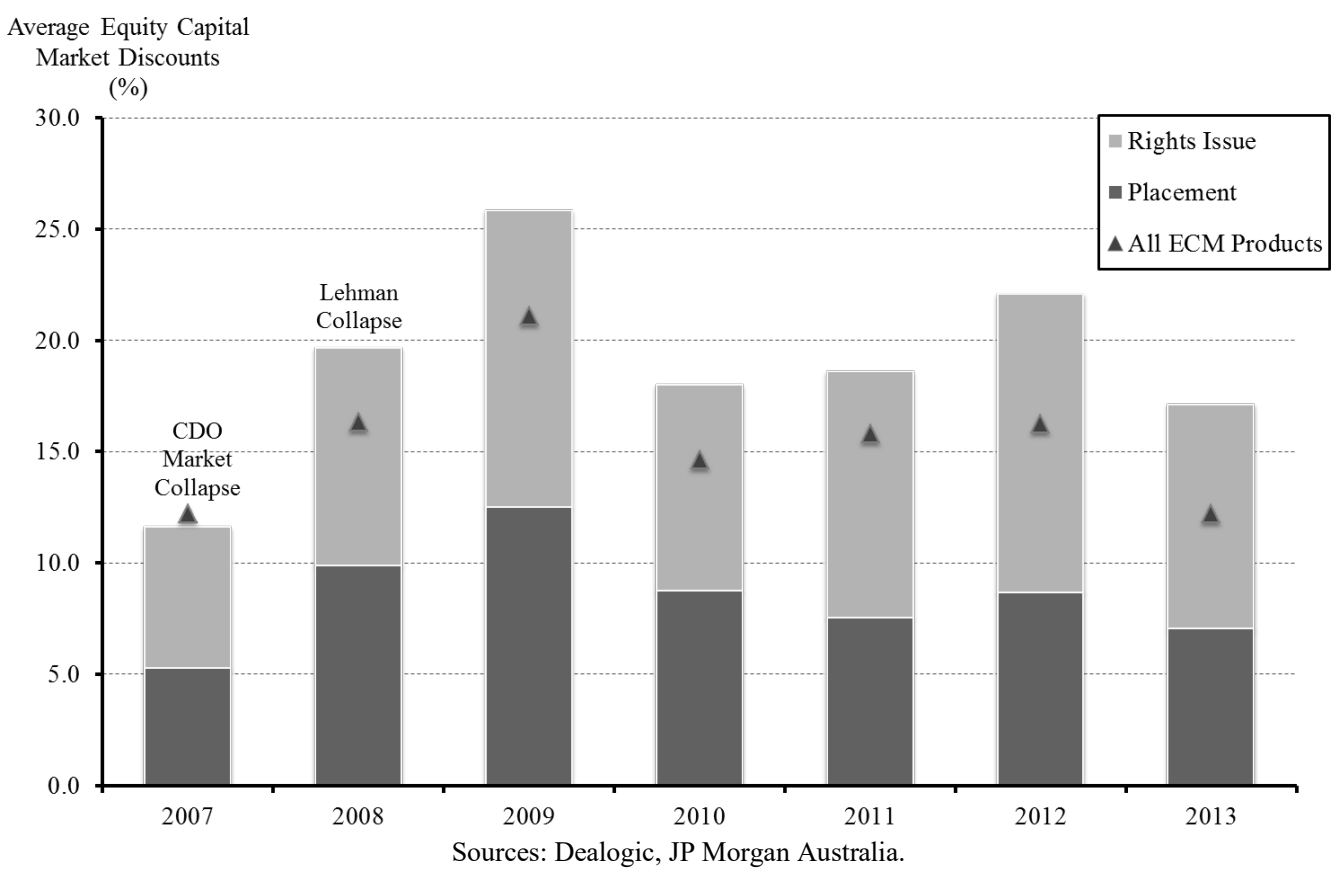

Indeed, Gray (2013b) explains that whether judged by Dividend Growth Models, the practice of independent experts, advice from investment banks currently raising equity capital for listed Australian firms, or other indicator variables from financial economics literature ${ }^{8}$, none point toward values for $K_{e}$ at multi-decade lows. On the contrary, the weight of evidence is that values for $K_{e}$ have been trading above long run averages. The key driver for higher average values for $K_{e}$ is that access to money is difficult during and after a financial crisis as Bernanke (1983) highlighted in the case of the Great Depression. The collapse of Lehman Brothers led to a rapid and marked contraction in the global supply of syndicated debt to industrial firms, and the market has not yet recovered. This is illustrated in Figure 4. Note the sharp and sustained contraction in the supply of syndicated debt from 2008. As pre-2008 syndicated debt facilities matured, firms were forced to cover funding gaps in balance sheets, and tapping the Equity Capital Markets (albeit at deep discounts and thus heightened values for $K e$ as Figure 3 highlights) has been an important source.

\footnotetext{
${ }^{8}$ See for example Petkova and Zhang (2005) who examine the MRP in relation to default premiums, term premiums and treasury bills and dividend yields.
} 
Figure 4: $\quad$ Global syndicated debt from 2004-2013

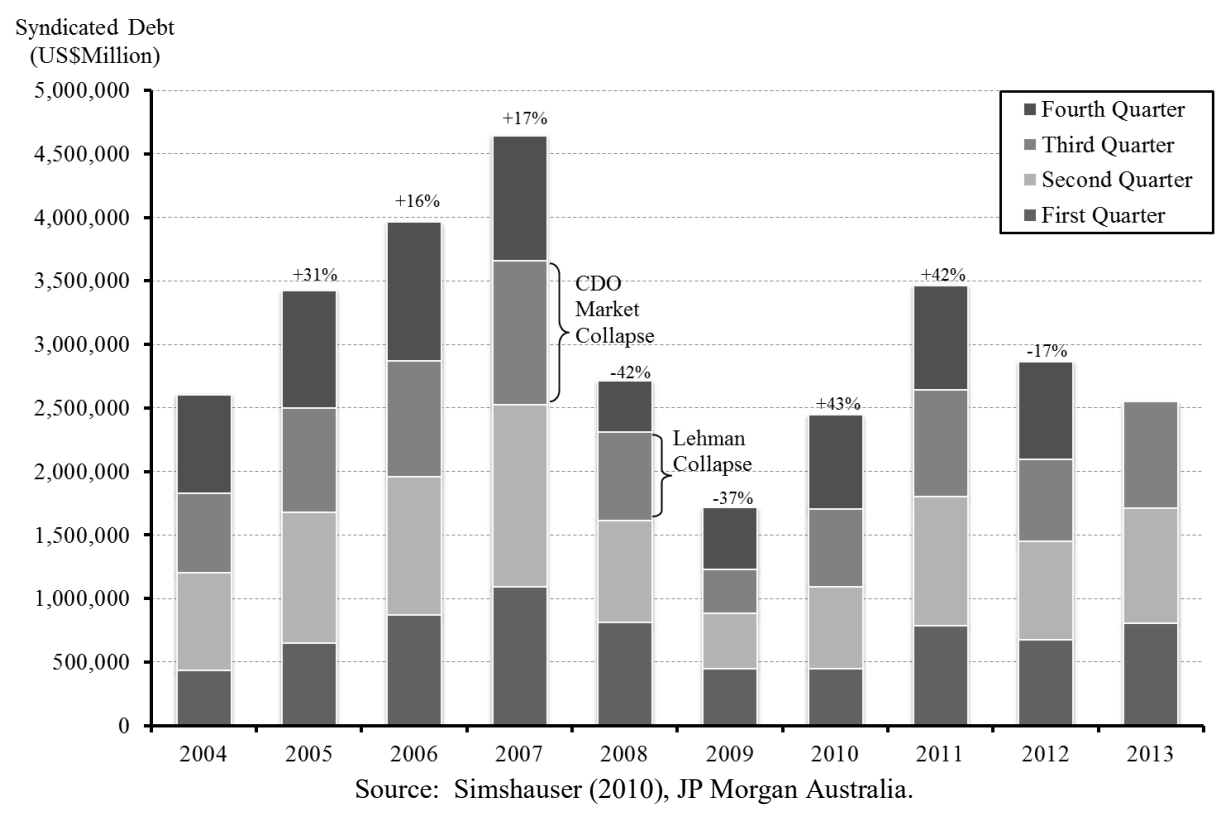

Does all of this mean that the CAPM is broken? The short answer is no. But its application requires considerable professional judgement in atypical capital market conditions. Ironically, and in spite of the wealth of empirical evidence to the contrary, many regulatory authorities in Australia have nonetheless persisted with applying the CAPM mechanistically. ${ }^{9}$ In my opinion, the appropriate application of the CAPM requires an historic $M R P$ value of $6.1 \%$ to be used with a long run average of the intercept term $R f$, and ideally, using the period prior to the collapse of Lehman Brothers in 2008. Another approach is to use an expanded value of MRP guided by conventional Dividend Growth Models (i.e. from $6.1 \%$ to a range of $7.4-8.3 \%)^{10}$ and a contemporaneous value for $R f$. This latter approach was adopted by IPART (2013) and is no less valid. Either method will result in similar and more appropriate outcomes than a mechanistic application, and should therefore represent a more reasonable estimate of the marginal cost of raising equity capital.

\subsection{Investor level taxation - gamma}

The CAPM outlined in equation (1) defines the cost of equity capital $K_{e}$ on a post-tax basis under a classical taxation system, that is, after corporate taxes and before investor-level taxes. Prima facie, with dividend imputation credits available to investors in Australia, the expected $K_{e}$ can be reduced to take into account the tax paid on behalf of stockholders. ${ }^{11}$ Monkhouse (1993) and Officer (1994) adjusted the CAPM to capture the effect of dividend imputation credits in assessing the effective post-tax cost of equity capital. The Officer (1994) adjustment to the CAPM model is as follows:

$$
K_{e}=\left[R_{f}+\left(R_{m}-R_{f}\right) \cdot \beta_{i}\right] \cdot\left[\frac{\left(1-\tau_{e}\right)}{\left(1-\tau_{e}\right) \cdot\left(1-\gamma_{i}\right)}\right]
$$

Where: $\tau_{e} \quad=$ the effective corporate taxation rate

$\gamma_{i} \quad=$ gamma, the utilization rate of imputation credits

\footnotetext{
${ }^{9}$ The exceptions to this are the NSW independent regulator, IPART (2013) and the Australian Energy Market Commission (2012).

${ }^{10}$ See Gray (2013b) for a summary of dividend growth model results.

${ }^{11}$ The dividend imputation system was introduced in Australia in 1987 to avoid the double taxation of equity returns. Prior to imputation, individual investors receiving the dividend stream were taxed twice; once as company profits and once more as dividends (i.e. as income in the hands of the individual investor). Following its introduction, credit was given to shareholders for the tax levied on their dividends at the company level. As a result, corporate tax may be considered a mixture of company and personal tax (Monkhouse, 1993).
} 
The corporate taxation rate $\tau$ in Australia at the time of writing was $30 \%$. However, the use of the full value of $\tau$ in equation (3) runs a high risk of an erroneous result for capital-intensive assets such as power stations due to their particularly large tax depreciation base. That is, it may overstate $K_{e}$ and induce Type I investment errors by firms, or may result in an overly generous profit benchmark for policymaking and regulation. The better view is to use the effective rate of Taxation $\tau_{e}$ which can be readily estimated by dynamic multi-period power project financial models. Using such a model, Simshauser and Ariyaratnam (2014) find values of $21.3 \%$ for coal plant and $22.8 \%$ for gas plant, for example.

In order to apply the imputation credit adjustment for gamma $(\gamma)$, a reasonable assessment of the mix and number of 'Australian Taxpaying' shareholders is required because dividend imputation credits can only be utilized by Australian taxpaying entities. Considerable debate exists as to the value of $\gamma$. For example, Hathaway and Officer (2004) argued the market places a positive value on franking credits for Australian firms. Using ATO data and company Franking Account Balances, they found that from 1988-2002, about $\$ 265$ billion had been paid in company taxes while Franking Account Balances totalled $\$ 77$ billion. Accordingly, $71 \%$ of theoretical franking credits had been accessed and $50 \%$ of distributed credits had been redeemed by taxpayers, thus concluding $\gamma=0.5$. However, Cannavan, Finn and Gray (2004, p.193) found that while the value of franking credits was initially valued at about $50 \%$ for high-yielding firms, following the introduction of "the 45-day rule" in $1997^{12}$, the value effects of imputation credits had a zero value. ${ }^{13}$ Gray (2013a) also reviewed a series of Independent Expert valuation reports for publicly listed companies from 2008-2013 and found practitioners routinely ignored $\gamma$ in Mergers \& Acquisition activity - which provides the practical evidence of the value currently ascribed to $\gamma$. In this article, $\gamma$ is therefore explicitly assumed to hold a zero value. However, should taxation law be changed at some point in the future such that $\gamma$ once again becomes valued, it would be appropriate to use equation (3) in the Australian context rather than equation (1).

\subsection{Weighted Average Cost of Capital}

For policymaking purposes, in most instances it will be appropriate to utilise pre-tax cash flow models of power generation discounted by the appropriate (pre-tax) Weighted Average Cost of Capital (WACC). Pre-tax cash flow models are known as Levelised Cost of Electricity Models. Under such conditions, since pre-tax and pre-financing cash flows are being discounted rather than post-tax and post-financing cash flows, equation (1) needs to be rearranged to produce a pretax value for $K_{e}$, the cost of debt needs to be introduced, and the cost of equity and debt capital need to be weighted according to their intended deployment:

$\operatorname{WACC}_{i}=\left\{\left(\frac{E_{i}}{V_{i}}\right) \cdot\left(\frac{\left.R_{f}+\left[R_{m}-R_{f}\right) \cdot \beta_{i}\right]}{\left[1-\tau_{e} \cdot(1-\gamma)\right]}\right)\right\}+\left\{\left(\frac{D_{i}}{V_{i}}\right) \cdot\left(R_{T}+C_{T}\right)\right\}$

Where $E_{i} \quad=$ is the value of equity of the $\mathrm{i}^{\text {th }}$ firm

$D_{i} \quad=$ is the value of debt of the $\mathrm{i}^{\text {th }}$ firm

$V_{i} \quad=E_{i}+D_{i}$

$R_{T} \quad=$ interest rate swap

$C_{T} \quad=$ credit spread

The process for determining $R_{T}$ is straight forward as there is a deep and liquid market for most instruments envisaged. The determination of $C_{T}$ requires more analysis to ensure observable transactions from debt markets represent 'suitable comparables' given the credit metric constraints facing the firm in question.

${ }^{12}$ The 45 day rule effectively meant that the trade of franking credits by foreign investors could only occur if scrip was held for 45 days around the date of dividend entitlement.

${ }^{13}$ The issue here is that Australia is a net importer of equity capital and therefore the marginal investor that sets the price of equities will be an overseas investor - who is unable to claim franking credits, hence a zero value for $\gamma$. 


\section{Levelised Cost of Electricity Model}

Broadly speaking, there are two methods for producing generalised Long Run Marginal Cost (LRMC) estimates for generation equipment, (1) dynamic multi-period power project finance models and (2) Levelised Cost of Electricity models. With dynamic power project finance models, a vastly greater number of inputs are required and in turn generate a more accurate result, particularly with respect to the timing and level of taxation, debt and equity costs. However with dramatically more computations involved, the risk of error is heightened. These models discount post-tax future cash flows to the expected cost of equity $K_{e}$ per equation (1). Levelised Cost of Electricity models on the other hand discount pre-tax, pre-financing cost and production streams by the expected WACC per equation (4). To be sure, for the purposes of developing power system cost estimates, the Levelised Cost of Electricity Model utilised in this article produces generalised LRMC estimates that are within $+/-2.0 \%$ of the more granular dynamic power project finance modelling results in Simshauser and Ariyaratnam (2014) holding all input assumptions constant. $^{14}$ The form of the Levelised Cost Model is set out below.

To begin with, since all outputs are expressed in nominal dollars, costs are increased annually by a forecast general inflation rate estimate (CPI) with prices escalating at a discount to the assumed CPI. Inflation rates for implied revenue streams $\pi_{j}^{R}$ and cost streams $\pi_{j}^{C}$ in period (year) $j$ are calculated in the model as follows:

$\pi_{j}^{R}=\left[1+\left(\frac{C P I \times \alpha_{R}}{100}\right)\right]^{j}$, and $\pi_{j}^{C}=\left[1+\left(\frac{C P I \times \alpha_{C}}{100}\right)\right]^{j}$

In this instance, $\alpha_{C}$ is the adjustment factor of 1.0 for costs and $\alpha_{R}$ relates to revenues and is set at 0.75 . The discounted value for $\alpha_{R}$ is intended to reflect single factor learning rates that characterise generating technologies over time. ${ }^{15}$

Energy output from each power plant (i) is a key variable in driving unit fuel cost, variable Operations \& Maintenance costs and the overall LRMC estimate. Energy output is calculated by reference to installed capacity $k^{i}$, capacity utilisation rate $C F_{j}^{i}$ and run time $t$, which in the Model is $8760 \mathrm{hrs}$ for each period $j$. Auxillary losses $A u x^{i}$ arising from on-site electrical loads (such as air compressors, lighting, induced and forced draft fans and so on) need to be deducted.

$\rho_{j}^{i}=k^{i} \cdot C F_{j}^{i} \cdot t \cdot\left(1-A u x^{i}\right)$

To determine the short run marginal cost of the $i^{\text {th }}$ plant in the $j^{\text {th }}$ period, the thermal efficiency for each generation technology $\zeta^{i}$ needs to be defined. The constant term ' 3600 ' ${ }^{16}$ is divided by the thermal efficiency variable to convert the result from per cent to $\mathrm{kJ} / \mathrm{kWh}$, which is then multiplied by the commodity cost of raw fuel $F^{i}$. Variable Operations \& Maintenance costs $v^{i}$ is also added to provide a pre-carbon short run marginal cost. To the extent that the plant has non-zero $\mathrm{CO}_{2}$ emissions and faces an emissions trading regime, the $\mathrm{CO}_{2}$ intensity of output for the $i^{\text {th }}$ plant needs to be computed along with the relevant $\mathrm{CO}_{2}$ price, $C P_{j}$. In order to define a value for plant carbon intensity $g^{i}$, the relevant combustion emissions factor $\dot{g}^{i}$ and fugitive $\mathrm{CO}_{2}$ emissions from the fuel source $\hat{g}^{i}$ are multiplied by the plant heat rate. Marginal running costs in the $j^{\text {th }}$ period is then calculated by the product of short run marginal production costs by energy output $\rho_{j}^{i}$ and escalated at the rate of $\pi_{j}^{C}$.

\footnotetext{
${ }^{14}$ The area of difference between post-tax, post-financing Power Project Finance Models and pre-tax, pre-finance Levelised Cost Models is isolated to the level, mix and timing estimates for taxation, debt and equity related costs.

${ }^{15}$ See Frontier Economics (2013) for a useful explanation of learning curves as they relate to power generation technologies.

${ }^{16}$ The derivation of the constant term 3600 is: 1 Watt $=1$ Joule per second and hence 1 Watt hour $=3600$ Joules .
} 
$\vartheta_{j}^{i}=\left\{\left[\left(\frac{\left(3600 / \zeta^{i}\right)}{1000} \cdot F^{i}+v^{i}\right)+\left(g^{i} \cdot C P_{j}\right)\right] \cdot \rho_{j}^{i} \cdot \pi_{j}^{C} \mid g^{i}=\left(\dot{g}^{i}+\hat{g}^{i}\right) \cdot \frac{\left(3600 / \zeta^{i}\right)}{1000}\right\}$

Fixed Operations \& Maintenance costs $f_{j}^{i}$ of the plant are measured in $\$ / \mathrm{MW} /$ year of installed capacity $F C^{i}$ and are multiplied by plant capacity $k^{i}$ and escalated.

$f_{j}^{i}=F C^{i} \cdot k^{i} \cdot \pi_{j}^{C}$

Earnings Before Interest Tax Depreciation and Amortisation (EBITDA), a frequently used measure in credit analysis, in the $j^{\text {th }}$ period can be defined as follows:

$\operatorname{EBITDA}_{j}^{i}=\left(R_{j}^{E}-\vartheta_{j}^{i}-f_{j}^{i}\right)$

Unless plant is acquired, capital costs associated with development involve a multi-period construction program. Capital costs are therefore defined as follows:

$X_{j}^{i}=-\sum_{k=1}^{N} C_{k} \cdot\left(1+K_{e}\right)^{-k}$

Ongoing capital spending for each period $j$ is determined as the inflated annual assumed capital works program.

$x_{j}^{i}=c_{j}^{i} \cdot \pi_{j}^{C}$

The general form for computing the Levelised Cost of Electricity can therefore be expressed as follows:

$P^{\varepsilon}=\sum_{j=1}^{N}\left[\left(-X_{j}^{i}+E B I T D A_{j}^{i}-x_{j}^{i}\right) \cdot\left(\left(1+W A C C_{i}\right)^{-(j)}\right)\right] / \sum_{j=1}^{N}\left[\left(\rho_{j}^{i} \cdot \pi_{j}^{R}\right) \cdot\left(1+W A C C_{i}\right)^{-(j)}\right]$

\subsection{LCOE for peaking power plant}

Certain adjustments are required to accommodate LRMC estimates for peaking plant. For base, semi-base and intermittent plant, the normal estimation procedure is to identify the relevant future cost streams and production streams which are in turn discounted by the $W A C C_{i}$. The value for $P^{\varepsilon}$ is found by solving equation (12), and one of the most sensitive variables is energy output $\rho_{j}^{i}$, which is in turn driven by the value for $C F_{j}^{i}$. In general, values for $C F_{j}^{i}$ are comparatively predictable in that base load plant have high capacity factors and intermittent plant, over time, exhibit output factors within a comparatively tight range given long-run average weather conditions. Peaking plant on the other hand exhibits fluctuating values for $C F_{j}^{i}$ due to the natural volatility inherent in short-run weather patterns and temporal shocks to the demand-supply balance. Accordingly, defining a single electricity price $P^{\varepsilon}$ for peaking plant is virtually meaningless in the absence of an expected fixed or 'sticky' $\overline{C F_{j}^{l}}$. And attempting to define a value for $P^{\varepsilon}$ is likely to render such a project unbankable in any event due to the uncertainty over values for $C F_{j}^{i}$ in practice. Consequently, peaking plant LRMC estimates require a different approach. In my opinion, the appropriate way to express levelised cost estimates for peaking plant is to define the 'carrying cost' of plant capacity, $\bar{F}_{0}$. This requires only small modifications to any levelised cost model as follows:

$\bar{F}_{0}=\left\{\sum_{j=1}^{N}\left[\left(-X_{j}^{i}+E B I T D A_{j}^{i}-x_{j}^{i}\right) \cdot\left(\left(1+W A C C_{i}\right)^{-(j)}\right)\right] / \sum_{j=1}^{N}\left[\left(\rho_{j}^{i} \cdot \pi_{j}^{R}\right) \cdot\left(1+W A C C_{i}\right)^{-(j)}\right] \mid \rho_{j}^{i}=\right.$ $100 \%$.t. $\left.k^{i} .\left(1-A u x^{i}\right) \forall j^{\wedge} \vartheta_{j}^{i}=0 \forall j\right\}$ 
In this instance, $C F_{j}^{i}$ is set to $100 \%$ while $\vartheta_{j}^{i}$ is set to zero. This has the effect of isolating all sunk capital and fixed operating costs - spreading them across the theoretical potential output of the plant and removing variable running costs. In practice $C F_{j}^{i}$ will be considerably less than $100 \%$ and $\vartheta_{j}^{i}$ will be non-zero. However, plant output will also receive the spot electricity price when producing and under most conditions will exceed marginal running costs $\vartheta_{j}^{i}$. The differential between the spot price and $\vartheta_{j}^{i}$ can be quite difficult to model, but in any event will be limited in each sub-period of $j$ by the strike price of call options sold by the plant ${ }^{17}$, and for the purposes of this article is assumed to be zero.

\section{Model Results}

Levelised Cost of Electricity Model results rely quite crucially on the engineering estimates of capital and maintenance costs of plant. These key variables along with fuel market costs are set out in Table 1. Note that the parameters have been derived from Worley Parsons (2012), ACIL Tasman (2012) and Frontier Economics (2013) who produce these estimates for the independent market operator (AEMO) and for the NSW independent economic regulator (IPART).

Table 1: Engineering \& Cost Parameters

\begin{tabular}{|c|c|c|c|c|c|c|c|c|c|}
\hline Model Variable & Unit & $i=$ & Black Coal & Black Coal & Brown Coal & CCGT* & CCGT* & Wind & OCGT* \\
\hline & & & QLD & NSW & VIC & (Low) & (High) & NEM & NEM \\
\hline Plant Capacity & MW & $k$ & 1000 & 1000 & 1000 & 400 & 400 & 200 & 450 \\
\hline Capacity Factor & $\%$ & $C F$ & 90.0 & 90.0 & 90.0 & 85.0 & 85.0 & 37.5 & $\mathrm{n} / \mathrm{a}$ \\
\hline Auxillary Load & $\%$ & Aux & 6.0 & 6.0 & 7.0 & 3.0 & 3.0 & 1.0 & 1.0 \\
\hline Thermal Efficiency & $\%$ & $\zeta$ & 39.0 & 39.0 & 28.0 & 50.0 & 50.0 & $\mathrm{n} / \mathrm{a}$ & 35.0 \\
\hline Raw Fuel & $\$ / G J$ & $F$ & 1.00 & 1.42 & 0.40 & 6.50 & 8.50 & $\mathrm{n} / \mathrm{a}$ & 8.50 \\
\hline Variable O\&M & \$/MWh & $v$ & 1.28 & 1.28 & 0.10 & 4.08 & 4.08 & 12.23 & 10.19 \\
\hline Fixed O\&M & \$/MW & $f$ & 52,768 & 52,768 & 36,700 & 10,188 & 10,188 & 40,750 & 4,075 \\
\hline Combustion Emissions & $\mathrm{kg} \mathrm{CO}_{2} / \mathrm{GJ}$ & $\dot{\mathrm{g}}$ & 90.2 & 90.2 & 92.0 & 50.6 & 50.6 & - & 50.1 \\
\hline Fugituive Emissions & $\mathrm{kg} \mathrm{CO}_{2} / \mathrm{GJ}$ & $\hat{\mathrm{g}}$ & 8.7 & 8.7 & 8.7 & 18.6 & 18.6 & - & 5.7 \\
\hline Carbon Price & $\$ / \mathrm{t}$ & $C P$ & 7.50 & 7.50 & 7.50 & 7.50 & 7.50 & 7.50 & 7.50 \\
\hline Capital Cost & $\$ / \mathrm{kW}$ & $X$ & 2,500 & 2,500 & 3,000 & 1,200 & 1,200 & 2,000 & 783 \\
\hline Capital Works & $\${ }^{\prime} 000$ & $x$ & 5,000 & 5,000 & 5,000 & 2,000 & 2,000 & 1,000 & 1,000 \\
\hline Useful Life & Years & $L$ & 40 & 40 & 40 & 30 & 30 & 25 & 30 \\
\hline
\end{tabular}

In addition to these parameters, financial and economic parameters are also required and are set out in Table 2.

Table 2: Financial Economic Parameters

\begin{tabular}{|l|c|c|r|}
\hline Model Variable & Unit & & \\
\hline Inflation & $\%$ & $C P I$ & 2.5 \\
\hline Risk Free Rate & $\%$ & $R_{f}$ & 5.8 \\
\hline Market Risk Premium (Rf-Rm) & $\%$ & $M R P$ & 6.1 \\
\hline Generation Asset Beta & $\#$ & $\beta_{\mathrm{a}}$ & 0.73 \\
\hline Equity Beta Factor VI & $\#$ & $\beta_{\mathrm{VI}}$ & 1.05 \\
\hline Equity Beta Factor IPP & $\#$ & $\beta_{\mathrm{IPP}}$ & 1.58 \\
\hline Tax Rate & $\%$ & $\tau_{c}$ & 30.0 \\
\hline Effective Tax Rate & $\%$ & $\tau_{e}$ & 21.3 \\
\hline 5Yr Interest Rate Swap & $\%$ & $\mathrm{R}_{\mathrm{T}}$ & 3.6 \\
\hline 12Yr Interest Rate Swap & $\%$ & $\mathrm{R}_{\mathrm{T}}$ & 4.5 \\
\hline PF Credit Spread (5 Yr) & bps & $\mathrm{C}_{\mathrm{T}}$ & 250 \\
\hline PF Credit Spread (12 Yr) & bps & $\mathrm{C}_{\mathrm{T}}$ & 300 \\
\hline BBB Credit Spread (5 Yr) & bps & $\mathrm{C}_{\mathrm{T}}$ & 180 \\
\hline BBB Credit Spread (12 Yr) & $b p s$ & $\mathrm{C}_{\mathrm{T}}$ & 225 \\
\hline
\end{tabular}

Sources: PWC (2013), Gray (2013a, 2013b), Nelson and Simshauser (2013).

\footnotetext{
${ }^{17}$ For investment purposes, the financial derivative product which effectively underwrites peaking plant in energy-only markets is a call option. The typical strike price of such instruments is $\$ 300 / \mathrm{MWh}$, with the call option premium $=\bar{F}_{0}$ in equilibrium.
} 
Figure 5 presents a stylised (pre-tax) cost of capital for merchant generation. Debt costs are based on blended 5- and 12-year pricing for varying credit quality. Note the range for project finance runs from about $50-67.5 \%$. Figure 5 specifically assumes that the pre-tax cost of equity is 'sticky' at the long run calculated value for $K_{e}$ for any credit quality below BBB. Credit ratings beyond A- are not contemplated due to inherent industry risk, otherwise the pre-tax $K_{e}$ varies according to the Asset Beta in Table 2. This is based on judgement and a lack of practical evidence to the contrary. Note that the WACC is minimised at a BBB credit rating.

Figure 5: $\quad$ Stylised pre-tax WACC for merchant generation

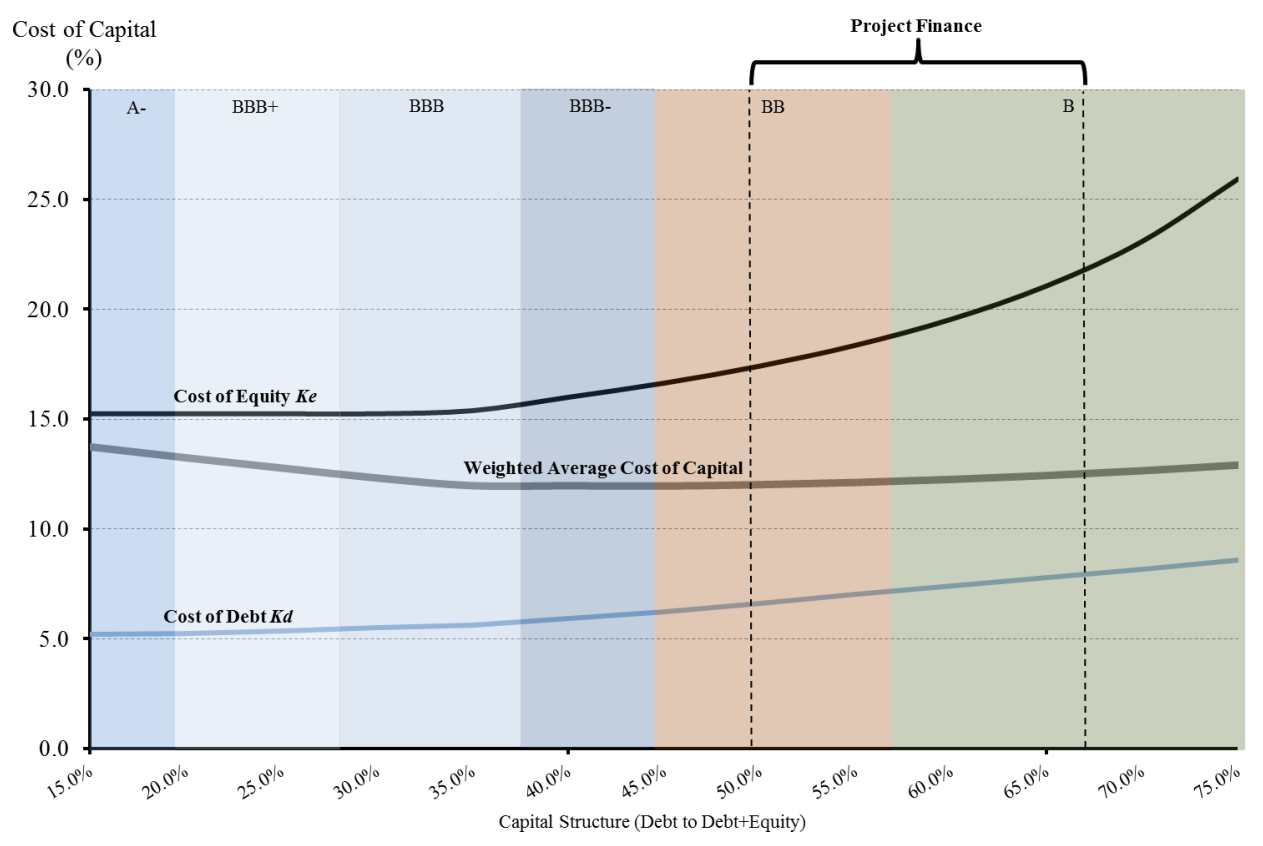

Combining the parameters in Tables 1 and 2 with the WACC (equation 4) and the two Levelised Cost of Electricity Models (equations 12 and 13) produces generalised LRMC estimates for multiple plant types on a unit cost basis. Figure 6 illustrates the results.

Figure 6: $\quad$ Levelised Cost of Electricity Model results

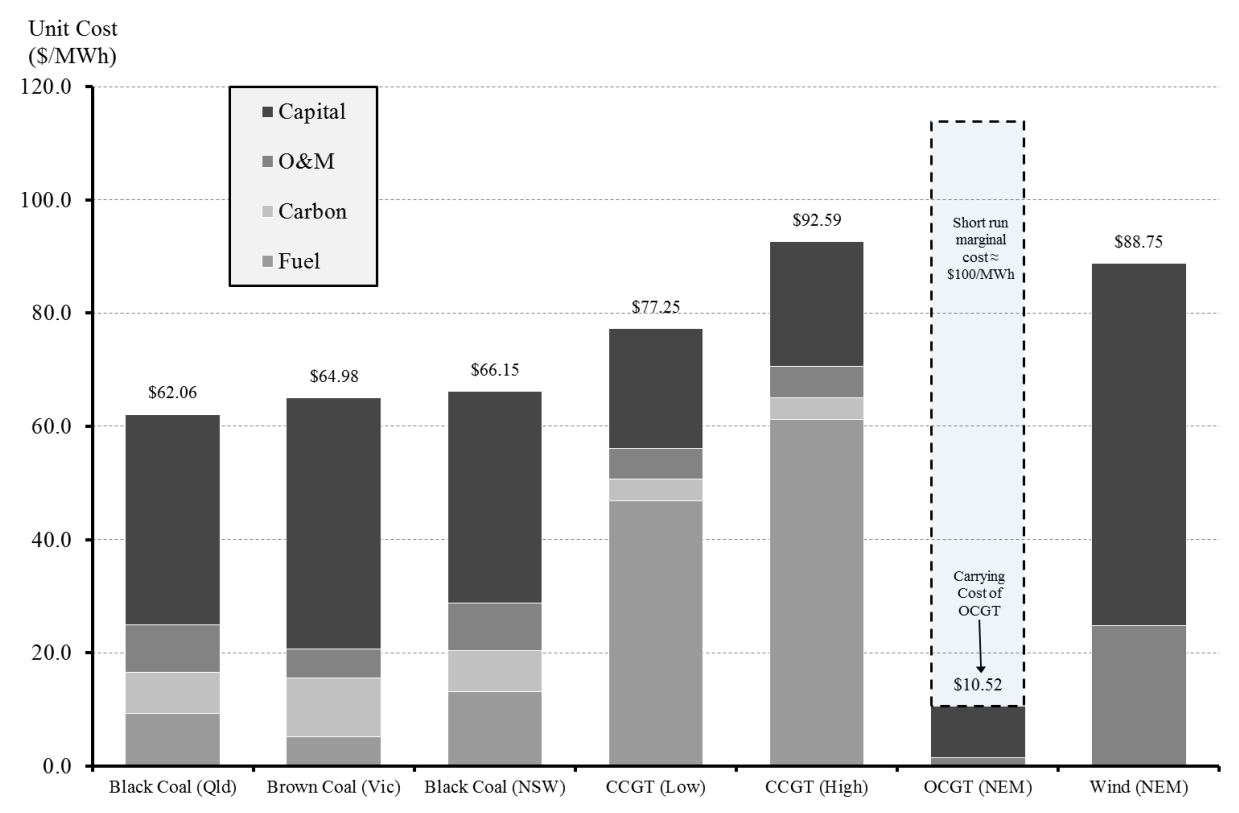


Each bar in Figure 6 is comprised of the individual cost elements of the plant, starting with Unit Fuel Costs $F^{i}$, Unit Carbon Costs $\left(g^{i} \cdot C P_{j}\right)$, fixed and variable Operations and Maintenance Costs and finally, capital costs which represents the cost of debt and equity on a pre-tax basis (and by implication incorporates annual taxation costs). All results are expressed in dollars per Megawatt Hour ( $\$$ MWh). The Levelised Cost Model's calculated unit energy cost $P^{\varepsilon}$ (and for OCGT plant unit capacity cost $\bar{F}_{0}$ ) is clearly marked above each bar. In this instance, returns from the plant exactly equal the $W A C C$ as set out in equation (4). To be perfectly clear on these results, $P^{\varepsilon}$ is the generalised LRMC or entry cost for each individual technology. The base load plant results represent market equilibrium for base load futures contract prices over the long run. Similarly, the carrying cost of OCGT capacity $\bar{F}_{0}$ represents equilibrium for call option contract prices over the long run, given an optimal stock and mix of plant.

\section{Application to policymaking}

The measurement of an appropriate WACC and in turn, generalised LRMC estimates, have broad application to policymaking in the electricity sector. Simshauser and Ariyaratnam (2014) provide one example by establishing cost-based benchmarks for the identification of potential market power abuse in competitive gross pool, energy-only electricity markets with high market price caps. The importance of correctly identifying an appropriate cost of capital in deriving estimates of power generation costs is aptly demonstrated in Figure 7. This tornedo chart presents the results of a sensitivity analysis whereby each of the key cost inputs in Table 1 have been varied by $+/-10 \%$ in the Levelised Cost of Electricity Model. Note that for coal plant in NSW, the WACC sensitivity produces the greatest variation to the generalised LRMC estimate.

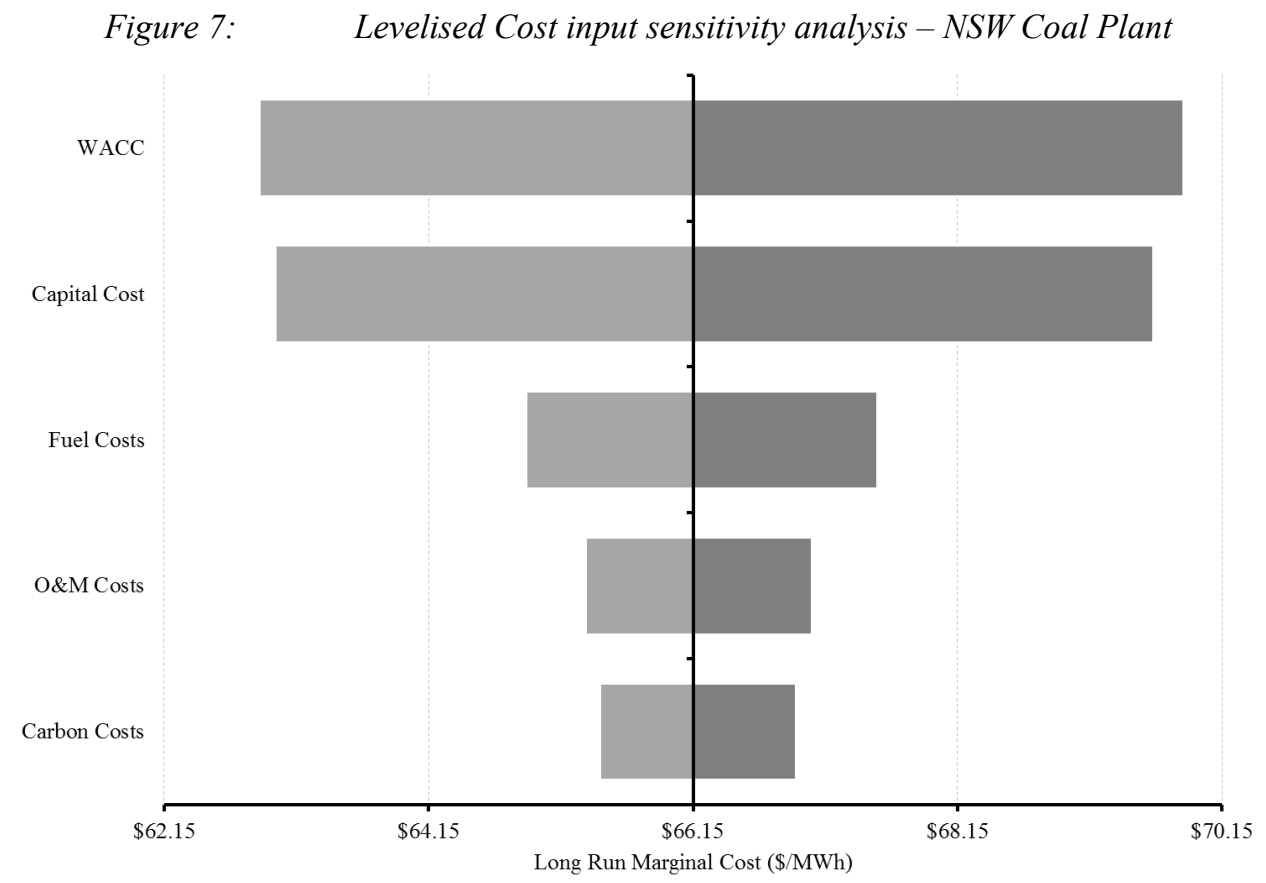

The impact arising from a mechanistic application of the CAPM during atypical capital market conditions (using equation (4) and contemporaneous bond yields from Figure 1) results in a WACC of $10.8 \%$. Correcting for atypical capital market conditions using the data inputs from Table 2 on the other hand produces a WACC of $12.1 \%$. This 130 basis point differential will produce non-trivial variations in power system cost estimates.

For the purposes of this analysis, it is also worth exploring other conditions whereby a WACC calculation can be erroneous. One recent example was in the determination of a 'regulated price cap' for rival retailers in the competitive New South Wales electricity market. A key component of the regulatory determination included generalised LRMC estimates of power generation $-\mathrm{a}$ 
critical component of supply-chain costs facing competitive retailers. Considerable effort was expended by the independent regulator, IPART (2012), in arriving at suitable engineering plant and fuel cost estimates, along with credible evidence on the cost of capital variables using live data from the capital markets. It is worth noting that IPART has been one of the few regulatory authorities in Australia that has correctly identified and accounted for atypical capital market conditions in producing their cost of capital estimates.

However, in IPART (2012), once data from the capital markets had been collated, two incompatible variables were (inadvertently) fused, viz. (1) the use of an investment-grade credit rating and associated (i.e. lower) credit margins from the market for BBB corporate bonds, and (2) the use of (higher) gearing levels more suited to a project finance. The capital structure selected comprised 50\% debt. Modelling in Simshauser and Ariyaratnam (2014) demonstrates that thermal plant in NSW could only sustain gearing levels of $35 \%$ while simultaneously retaining a BBB credit rating. Table 3 presents an analysis of global project financings covering 1,953 transactions and 3,772 tranches of debt commencing from the first power project financing in 1981 through to the time of writing across 89 countries. (The data has also been separated into pre- and post-GFC period financings, further underscoring the presence of atypical capital market conditions). Less than $7 \%$ of transactions had a parent company guarantee and only a portion of these parent companies would have investment grade credit ratings. ${ }^{18}$ The implication here is that project financings will not involve credit-rated debt, and so project debt margins will, ceteris paribus, be higher than that associated with investment-grade bond issuance. For example, BBB spreads for Australian corporate bonds (from Figure 2) averaged 160bps between 2000-2013. Australian project financing spreads averaged $243 \mathrm{bps}$ over the same period - fully 83 basis points higher. The IPART (2012) approach was the result of misinterpreting the capital structure constraints facing the business combination selected.

\begin{tabular}{|c|c|c|c|c|c|}
\hline Period & $\begin{array}{r}\text { Issuance } \\
(\mathrm{A} \$ \mathrm{~m})\end{array}$ & $\begin{array}{r}\text { Deals } \\
(\#)\end{array}$ & $\begin{array}{r}\text { Tranches } \\
(\#)\end{array}$ & $\begin{array}{l}\text { Tenor } \\
\text { (Yrs) }\end{array}$ & $\begin{array}{r}\text { Avg Spread } \\
\text { (bps) }\end{array}$ \\
\hline \multicolumn{6}{|c|}{ Global - 89 Countries } \\
\hline $1981-2006$ & 555,703 & 784 & 1,441 & 10.4 & 133 \\
\hline 2007-2013 & 490,103 & 1,169 & 2,331 & 12.1 & 262 \\
\hline Total & $1,045,806$ & 1,953 & 3,772 & 10.9 & 187 \\
\hline \multicolumn{6}{|l|}{ Australia } \\
\hline 1994-2006 & 8,913 & 32 & 49 & 10 & 113 \\
\hline $2007-2013$ & 16,513 & 28 & 44 & 6 & 287 \\
\hline Total & 25,426 & 60 & 93 & 8 & 244 \\
\hline
\end{tabular}

The impact of such a decision in policy formulation can be quantified using equation (4) and shifting the value of $\left(\frac{D_{i}}{V_{i}}\right)$ from $35 \%$ to $50 \%$. This has the effect of reducing the WACC from $12.1 \%$ to $10.8 \%$ - by coincidence - the same result as a mechanistic application of the CAPM. Given both examples above resulted in erroneous WACC estimates of $10.8 \%$, it is worth analysing the effects on LRMC estimates. This can be done for each thermal technology (using NSW data) via the Levelised Cost of Electricity Model. The results are presented in Figure 8. Note that the Black Coal plant experiences the largest impact.

\footnotetext{
${ }^{18}$ Our database shows all transactions listed in Reuters from 1981 through to June 2013. However, our data on parent company guarantors only covers 1080 transactions. Of these 1080 transactions, 70 or $6.48 \%$ involved a guarantor - and it was not clear that those guarantors necessarily had a credit rating in any event.
} 
Figure 8: $\quad$ Generalised LRMC estimates for NSW plant with WACC at $10.8 \%$ and $12.1 \%$

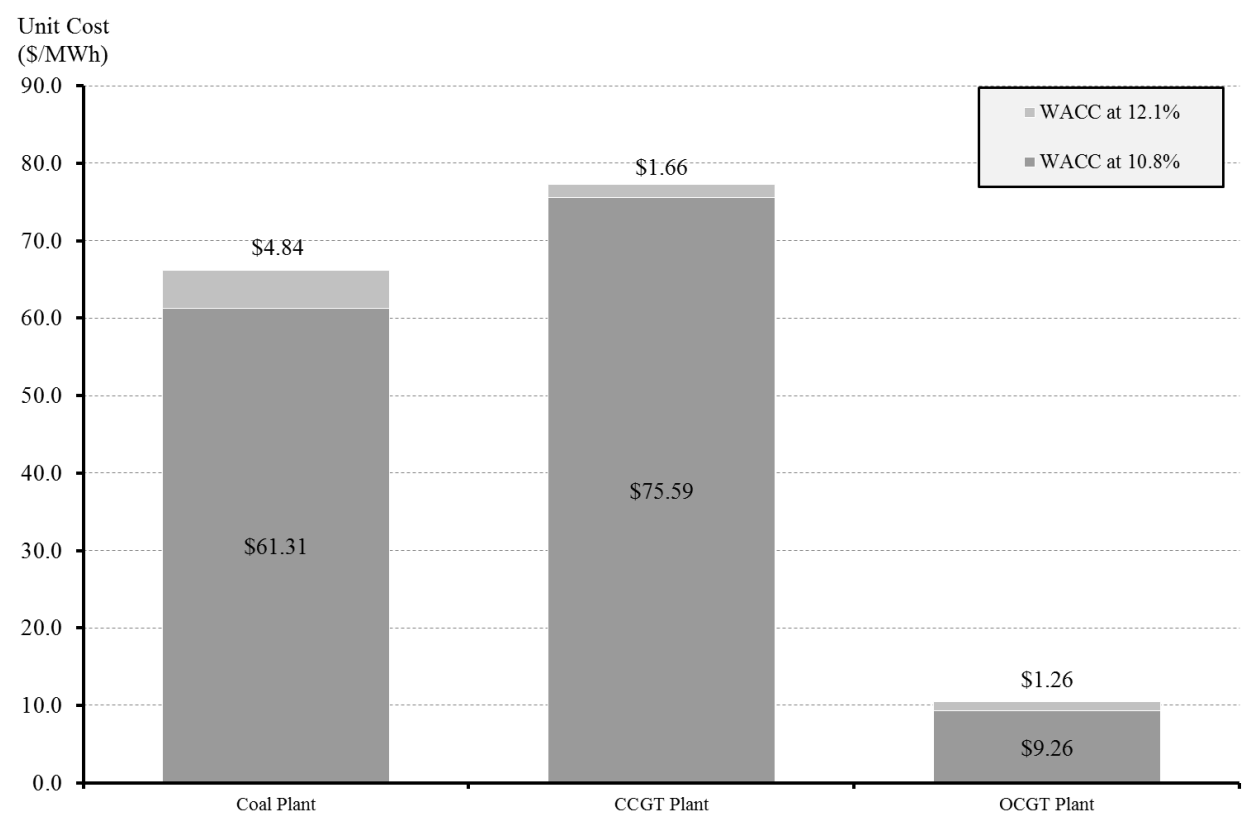

To analyse the impact on the total power system, a partial equilibrium model is required. Central Electricity Generating Board of England \& Wales' Chief Economist, Tom Berrie, developed a useful static partial equilibrium model which helps to quantify the effects on system-wide power generation cost estimates. This framework is presented in Figures 9.1 and 9.2. A third Price Duration Chart (Figure 9.3) has been added to Berrie's (1967) two-chart framework. Figure 9 assumes WACC is set to $12.1 \%$ while Appendix I uses a $10.8 \%$ WACC. Tables 4 and 5 present the detailed economic and production statistics for both scenarios and a differential analysis is presented in Table 6 .

Figure 9.1 presents Marginal Running Cost Curves for the three generating technologies of base (black coal), semi-base (CCGT) and peaking (OCGT) plants. The y-axis intercept for each technology represents the fixed and sunk costs $\left(\bar{F}_{n}\right)$ while the slope of the curves represents marginal running costs $\left(\vartheta_{n}\right)$. The x-axis measures plant capacity factor $C F_{j}^{i}$ from equation (6). Note intercepts $t_{1}$ and $t_{2}$ identify the point at which the most efficient plant switches to the next technology, given the rich blend of fixed and variable costs of the plant technologies.

Figure 9.2 illustrates a Load Duration Curve. This is a representation of the 17,520 half-hourly electricity load points in a year but ranked in descending order rather than as a time-series, with the $y$-axis measuring electricity load (MW) and the x-axis measuring 'time exceeded'. ${ }^{19}$ Figure 9.3 is the corresponding Price Duration Curve, that is, the spot price set in each half-hour period in Figure 9.2 under the conditions of a gross pool, energy-only, uniform first-price auction clearing mechanism, with the $y$-axis measuring price and the $\mathrm{x}$-axis also measuring 'time exceeded'.

The Figure 9 static partial equilibrium model assumes a perfect transmission system and as a result there are no constraints over the dispatch order of generating equipment. The model also assumes that generators are free to install perfectly divisible plant capacity with perfect plant availability (and hence no requirement for a reserve plant margin) in any combination that satisfies differentiable equilibrium conditions.

\footnotetext{
${ }^{19}$ In this instance, live FY13 half-hourly load data from the NSW region has been used.
} 
Figure 9: $\quad$ Static Partial Equilibrium Model: NSW Region FY13-WACC at 12.1\%

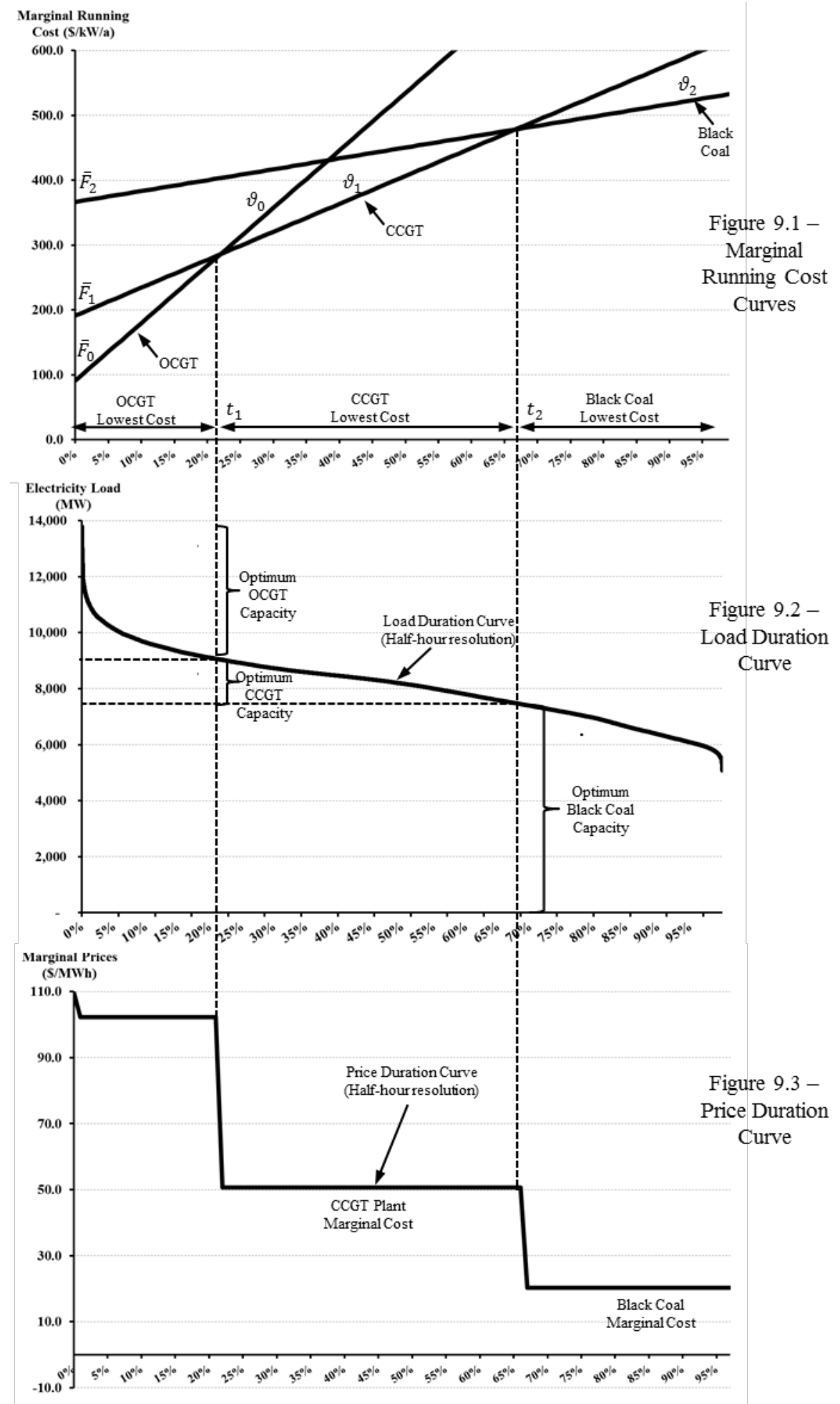

Table 4 sets out the detailed energy production and cost results from the model and notes that the system average spot price of $\$ 66.15 / \mathrm{MWh}$ (i.e. the average of results in Figure 9.3) falls short of 
system average cost $(\$ 76.86 / \mathrm{MWh})$ by the amount roughly equivalent to $\bar{F}_{0}-$ that is, $\$ 10.71 / \mathrm{MWh}$ (per Figure 7). ${ }^{20}$

Table 4: Static Partial Equilibrium Results - WACC at $12.1 \%$

\begin{tabular}{lccccccc}
\hline Plant Type & $\begin{array}{c}\text { Capacity } \\
(\mathrm{MW})\end{array}$ & $\begin{array}{c}\text { Production } \\
(\mathrm{GWh})\end{array}$ & $\begin{array}{c}\text { Fixed Costs } \\
(\mathbf{\$ m})\end{array}$ & $\begin{array}{c}\text { Running Costs } \\
(\$ \mathrm{~m})\end{array}$ & $\begin{array}{c}\text { Total Costs } \\
(\$ \mathrm{~m})\end{array}$ & $\begin{array}{c}\text { Avg Unit Cost } \\
(\$ / \mathrm{MWh})\end{array}$ & $\begin{array}{c}C F_{j}{ }^{i} \\
(\%)\end{array}$ \\
\hline Black Coal & 7,553 & 58,755 & 2,769 & 1,196 & 3,965 & 67.48 & 89 \\
CCGT & 1,509 & 9,261 & 289 & 469 & 758 & 81.84 & 70 \\
OCGT & 4,725 & 2,909 & 431 & 297 & 729 & 250.43 & 7 \\
\hline Total & 13,788 & 70,925 & 3,489 & 1,962 & 5,451 & 76.86 & 59 \\
Average Spot Price & & & & & 66.15 & \\
\multicolumn{2}{l}{ Diff (Avg Unit Cost less Avg Spot Price) } & & & & 10.71 & \\
\hline
\end{tabular}

If the limiting assumptions of perfect plant divisibility and availability were relaxed, system average cost would rise above $\$ 76.86 / \mathrm{MWh}$ and the competitive spot price under conditions of intense competition would fall as discrete and lumpy power plant blocks were added and reserve plant purposefully added to meet reliability constraints. In Table 5, the results of the partial equilibrium analysis have been re-simulated to take into account a mechanistic application of the CAPM, with the WACC reduced from $12.1 \%$ to $10.8 \%$. Here, system average cost falls from $\$ 76.86 / \mathrm{MWh}$ to $\$ 72.26 / \mathrm{MWh}$.

Table 5: Static Partial Equilibrium Results - WACC at 10.8\%

\begin{tabular}{lccccccc}
\hline Plant Type & $\begin{array}{c}\text { Capacity } \\
(\mathrm{MW})\end{array}$ & $\begin{array}{c}\text { Production } \\
(\mathrm{GWh})\end{array}$ & $\begin{array}{c}\text { Fixed Costs } \\
(\$ \mathrm{~m})\end{array}$ & $\begin{array}{c}\text { Running Costs } \\
(\$ \mathrm{~m})\end{array}$ & $\begin{array}{c}\text { Total Costs } \\
(\$ \mathrm{~m})\end{array}$ & $\begin{array}{c}\text { Avg Unit Cost } \\
(\$ / \mathrm{MWh})\end{array}$ & $\begin{array}{c}C F j i \\
(\%)\end{array}$ \\
\hline Black Coal & 7,839 & 60,569 & 2,617 & 1,233 & 3,850 & 63.56 & 88 \\
CCGT & 1,267 & 7,621 & 225 & 386 & 611 & 80.11 & 69 \\
OCGT & 4,682 & 2,736 & 385 & 280 & 665 & 243.03 & 7 \\
\hline Total & 13,788 & 70,925 & 3,227 & 1,898 & 5,125 & 72.26 & 59 \\
Average Spot Price & & & & & 63.60 & \\
Diff (Avg Unit Cost less Avg Spot Price) & & & & 8.67 & \\
\hline
\end{tabular}

The differential analysis in Table 6 reveals the major changes in the optimal power system model results. First, with a lower WACC, the running cost curves (in Figure 9.1 and Figure A.1) for Black Coal plant shift proportionally lower than other plant technologies thus increasing their mix in the optimal portfolio (i.e. Black Coal plant $+286 \mathrm{MW}$ ), with corresponding reductions in CCGT $(-242 \mathrm{MW})$ and OCGT (-44MW) plant. This structural change in the technology composition has the beneficial effect of reducing overall running costs (i.e. fuel costs) by $\$ 64$ million. Fixed costs are also reduced by $\$ 262$ million. However, the reduction in fixed costs is due to the cost of capital being mis-priced by 130 basis points, thus representing a wealth transfer, not an increase in welfare.

Table 6: Change in power system plant and costs (10.8\% WACC vs. $12.1 \%$ WACC)

\begin{tabular}{lccccccc}
\hline Plant Type & $\begin{array}{c}\text { Capacity } \\
(\mathrm{MW})\end{array}$ & $\begin{array}{c}\text { Production } \\
(\mathrm{GWh})\end{array}$ & $\begin{array}{c}\text { Fixed Costs } \\
(\$ \mathrm{~m})\end{array}$ & $\begin{array}{c}\text { Running Costs } \\
(\$ \mathrm{~m})\end{array}$ & $\begin{array}{c}\text { Total Costs } \\
(\$ \mathrm{~m})\end{array}$ & $\begin{array}{c}\text { Avg Unit Cost } \\
(\$ / \mathrm{MWh})\end{array}$ & $\begin{array}{c}C F j i \\
(\%)\end{array}$ \\
\hline Black Coal & 286 & 1,814 & -152 & 37 & -115 & -3.91 & -1 \\
CCGT & -242 & $-1,640$ & -64 & -83 & -147 & -1.72 & -1 \\
OCGT & -44 & -174 & -46 & -18 & -64 & -7.40 & -0 \\
\hline Total & 0 & 0 & -262 & -64 & -326 & -4.59 & 0 \\
Average Spot Price & & & & & -2.55 & \\
Diff (Avg Unit Cost less Avg Spot Price) & & & & -2.04 & \\
\hline
\end{tabular}

${ }^{20}$ The value for $\bar{F}_{0}$ is an important one as it also defines the 'missing money' in an energy-only market under conditions of intense competition and perfect plant divisibility and availability. The term 'missing money' was first raised by Cramton and Stoft (2006), and later Joskow (2006), and describes a situation whereby market price caps (set low to constrain market power) adversely affect average clearing prices thus resulting in inadequate returns to investors in generation plant. Steed and Laybutt (2011) identify c. $\$ 6$ billion in 'missing money' in the NEM from 2000-2010 even with a market price cap of $\$ 10,000 / \mathrm{MWh}$. 
The differential between the two scenarios equates to $\$ 4.59 / \mathrm{MWh}$, and in a market with total load of $70,925 \mathrm{GWh}$ pa, could be thought of as a wealth transfer of $\$ 326$ million per annum. Of course, the wholesale electricity market in NSW is highly competitive and prices are deregulated. But where such analysis is used to guide policymaking, using an inappropriate WACC can result in unintended consequences. This is of course more than a theoretical possibility. The case of the IPART (2012) determination provides one example and essentially represented a wealth transfer of $\$ 92$ million per annum - the lower amount due to the fact that the determination applied to 20,000 GWh of residential and small business load as opposed to the entire system load of 70,925 GWh. To be sure, once the incompatible WACC constructs were highlighted to the independent regulator, suitable adjustments were made in IPART (2013) during the next regulatory reset.

\section{Concluding Remarks}

When using the CAPM in atypical capital market conditions, a mechanistic approach will produce intuitively erroneous results. During atypical market conditions, longer-run average values will provide more credible outcomes but should nonetheless be tested against bestestimates for marginal capital raisings to ensure they are reasonable - the approach adopted by IPART (2013). There is a wealth of investment banking experience available to policymakers and regulators to draw upon if in doubt.

The impact of using contemporaneous values for the intercept term $R f$ in the CAPM was found to result in an erroneous reduction in the power generation WACC of 130 basis points. Sensitivity results from the Levelised Cost of Electricity Model demonstrated that the cost of capital produced the most significant change to LRMC estimates of all key cost inputs, an outcome not unexpected given the highly capital intensive power generating equipment. When applied to a NSW example, the headline result was a \$326 million wealth transfer. Such an outcome would hardly send firms into financial distress in a $\$ 5.5$ billion pa power system. But holding debt costs constant, a time inconsistency problem would predictably emerge. The literature on the dynamic or time inconsistency problem can be traced back to Kydland and Prescott (1977, p.486), who observed in the case of energy in the USA:

...rational agents are not making investments in new sources of oil in anticipation that price controls will be instituted in the future. Currently there are those who propose to tax away "excessive" profits of the oil companies with the correct argument that this will not affect past decisions. But rational agents anticipate that such appropriations may be made in the future, and this expectation affects their current investment decisions, thereby reducing future supplies...

In the world's most capital-intensive industry - the energy sector - it is difficult to imagine a more damaging exogenous variable to achieving efficient outcomes than time or dynamic inconsistency. Thus is the importance of establishing robust cost of capital estimates in policymaking. 


\section{References}

ACIL Tasman, (2012), "Fuel cost projections", Report to AEMO, ACIL Tasman Publication, Brisbane. Available at www.aemo.com.au

AEMC: Australian Energy Market Comission, (2012), "Rule Determination - National Electricity Amendment (Economic Regulation of Network Service Providers) Rule 2012", AEMC Publication Sydney. Available at www.aemc.gov.au

Averch, H. and Johnson, L. (1962), "Behaviour of the firm under regulatory constraint", American Economic Review, 52(1): 1052-1069.

Batabyal, A. (1996), "Consistency and Optimality in a dynamic game of pollution control II: monopoly", Environmental and Resource Economics, Vol.8, pp 315-330.

Bernanke, B. (1983), "Nonmonetary effects of the financial crisis in the propagation of the great depression", The American Economic Review, 73(3): 257-276.

Berrie, T. (1967), "The economics of system planning in bulk electricity supply", Electrical Review, 22(2): 425-428.

Brailsford, T., Handley, J. and Maheswaran, K. (2012), "The historical equity risk premium in Australia: post-GFC and 128 years of data", Accounting and Finance, 52(2012): 237-247.

Brito, D., Pereira, P. and Vareda, J. (2011), “Investment, dynamic consistency and the sectoral regulator's objective", $8^{\text {th }}$ Asia-Pacific Regional ITS Conference, Taipei 2011. Available at http://econstor.eu/bitstream/10419/52341/1/673079651.pdf. Accessed July 2013.

Cannavan, D., Finn, F. and Gray, S. (2004), "The value of dividend imputation tax credits in Australia", Journal of Financial Economics, 73(2004): 167-197.

Cramton P. and Stoft, S. (2006), "The convergence of market designs for adequate generating capacity with special attention to the CAISOs resource adequacy problem", Cambridge, MA: Center for Energy and Environmental Policy Research.

Fama, E. and French, R. (1997), "Industry costs of equity", Journal of Financial Economics, 43(1997): 153-193.

Frontier Economics, (2013), "Input assumptions for modelling wholesale electricity costs - draft report prepared for IPART”, Frontier Economics Publication, April, Melbourne.

Gray, S. (2013a), "Evidence on the required return on equity from independent expert reports", SFG Consulting, Mimeo., Brisbane.

Gray, S. (2013b), “The required return on equity since the global financial crisis", SFG Consulting, Mimeo., Brisbane.

Hathaway, N. and Officer, R. (2004), "The value of imputation tax credits", available at http://www.agl.com.au/Downloads/050427_App-1-Imputation-Tax-Credits\%E2\%80\%93Hathaway-and-

Officer_Corporate_Government-Submissions.pdf

Haubrich, J. (2000), "Waiting for policy rules", Economic Commentary, Federal Reserve Bank of Cleveland, January 2000, pp1-5. Available at http://www.clevelandfed.org/research/Commentary/2000/0115.htm

IPART: Independent Pricing and Regulatory Tribunal, (2012), Changes in the regulated retail electricity prices from 1 Jult 2012", IPART publication, Sydney. Available at www.ipart.nsw.gov.au

IPART: Independent Pricing and Regulatory Tribunal, (2013), "WACC Methodology", IPART publication, Sydney. Available at www.ipart.nsw.gov.au 
Joskow, P. (2006), "Competitive electricity markets and investment in new generating capacity", AEIBrookings Joint Centre for Regulatory Studies, Working Paper No.06-14.

Kydland, F. and Prescott, E. (1977), "Rules rather than discretion: the inconsistency of optimal plans", The Journal of Political Economy, 85(3): 473-492.

Lintner, J. (1965), "The valuation of risk assets and the selection of risky investment in stock portfolios and capital budgets", Review of Economics and Statistics, 47(Feb): 13-37.

Monkhouse, P. (1993), "The Cost of Equity under the Australian Imputation Tax System", Journal of Accounting and Finance, November, pp. 1-18.

Nelson, T., Kelley, S., Orton, F. and Simshauser, P. 2010, "Delayed carbon policy certainty and electricity prices in Australia", Economic Papers, 29(4): 446-465.

Nelson, J. and Simshauser, P. (2013), “Is the Merchant Power Producer a Broken Model?", Energy Policy, 53(Feb): 298-310.

Neuhoff, K. and De Vries, L. (2004), "Insufficient incentives for investment in electricity generation", CMI Working Paper 42, Cambridge.

Officer, R. (1994), "The cost of capital of a company under an imputation tax system", Journal of Accounting and Finance, May, pp. 1-17.

Petkova, R. and Zhang, L. (2005), "Is value riskier than growth", Journal of Financial Economics, 78(2005): 187-202.

PwC: Pricewaterhouse Coopers, (2013), "Guidance on the cost of capital for new plant entry to the National Electricity Market", PwC Report to AGL Energy Ltd, Sydney.

Rathmann, M., de Jager, D. amd de Lovinfosse, I., Breitschopf, B., Burgers, J. and Weöres, B. 2011, "Towards triple-A policies: More renewable energy at lower cost", Re-Shaping Project: Intelligent Energy - Europe, ALTENER. Available at www.reshaping-res-policy.eu,

Rogoff, (1985), "The optimal degree of commitment to an intermediate monetary target", The Quarterly Journal of Economics, 100(4): 1169-1189.

Sharpe, W. (1964), "Capital Asset Prices: a theory of market equilibrium under conditions of risk", Journal of Finance, 19(Sept): 425-442.

Shapiro, J., Whyte, J. and Drummond, S. (2013), "Boomers force up dividends", Australian Financial Review, 2 November.

Simshauser, P. (2010), "Resource adequacy, capital adequacy and investment uncertainty in the Australian power market", The Electricity Journal, 23(1): 67-84.

Simshauser, P. and Ariyaratnam, J. (2014), “What is normal profit in power generation?", Journal of Financial Economic Policy, Vol.6: article in-press.

Simshauser, P. and Nelson, T. (2012), "The second-round effects of carbon taxes on power project finance", Journal of Financial Economic Policy, 4(2): 104-127.

Simshauser, P. and Nelson, T. (2014), "Solving for $x$ - the New South Wales Gas Supply Cliff", $A G L$ Applied Economics \& Policy Working Paper No.40, AGL Energy Publication, Brisbane.

Steed, J., \& Laybutt, C. (2011). Merchant Utilities: Who gets the missing money? Sydney: J.P. Morgan Securities Australia. 
Taylor, H. (1985), "Time inconsistency: a potential problem for policymakers", Business Review - Federal Reserve Bank of Philadelphia, Mar-Apr 1985, pp. 3-12

Thompson, A. and Formby. J. (1993), Economics of the Firm: Theory and Practice, Prentice Hall.

Varadarajan, U., Nelson, D., Pierpont, B. and Hervé-Mignucci, M. 2011, "The Impacts of Policy on the Financing of Renewable Projects: A Case Study Analysis", Climate Policy Initiative, San Francisco.

Virag, G. (1999), Independence of a Regulatory Institution . A Means to Alleviate Credibility Problems in the CEE Countries, Case CEU Working Paper Series, Center for Social and Economic research, Central European University, Warsaw. Available at

http://www.nbportal.pl/library/pub_auto_B_0001/KAT_B2170.PDF

Worley Parsons (2012), “Cost of Construction - New Generation Technology”, Report to AEMO, Worley Parsons Publication, Melbourne. Available at www.aemo.com.au 
Appendix I: Static Partial Equilibrium Model - NSW Region FY13 - WACC at 10.8\%

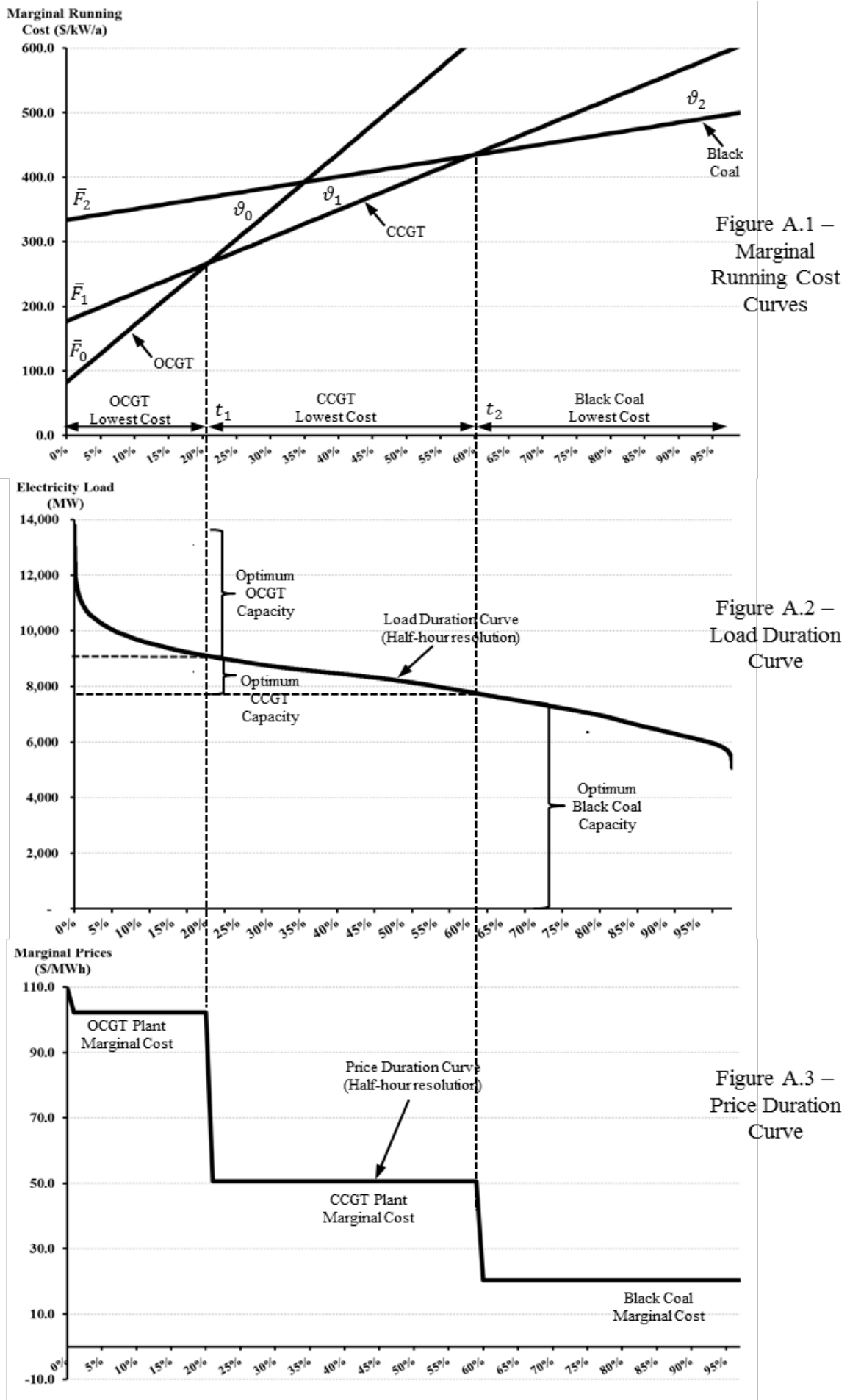

